\title{
Quantitative roughness characterization of geological surfaces and implications for radar signature analysis
}

\section{Dierking, Wolfgang}

Published in:

I E E E Transactions on Geoscience and Remote Sensing

Link to article, DOI:

$10.1109 / 36.789638$

Publication date:

1999

Document Version

Publisher's PDF, also known as Version of record

Link back to DTU Orbit

Citation (APA):

Dierking, W. (1999). Quantitative roughness characterization of geological surfaces and implications for radar signature analysis. I E E E Transactions on Geoscience and Remote Sensing, 37(5), 2397-2412. https://doi.org/10.1109/36.789638

\section{General rights}

Copyright and moral rights for the publications made accessible in the public portal are retained by the authors and/or other copyright owners and it is a condition of accessing publications that users recognise and abide by the legal requirements associated with these rights.

- Users may download and print one copy of any publication from the public portal for the purpose of private study or research.

- You may not further distribute the material or use it for any profit-making activity or commercial gain

- You may freely distribute the URL identifying the publication in the public portal 


\title{
Quantitative Roughness Characterization of Geological Surfaces and Implications for Radar Signature Analysis
}

\author{
Wolfgang Dierking
}

\begin{abstract}
Stochastic surface models are useful for analyzing in situ roughness profiles and synthetic aperture radar (SAR) images of geological terrain. In this paper, two different surface models are discussed: surfaces with a stationary random roughness (conventional model) and surfaces with a power-law roughness spectrum (fractal model). In the former case, it must be considered that for short profiles $\left(L<200 l_{0}\right)$, the measured values of rms-height $s$ and correlation length $l$ may be significantly smaller than the intrinsic values $s_{0}$ and $l_{0}$. In the latter case, rms-height and correlation length depend on the profile length $L$, and the surface is better characterized by slope and offset of the roughness spectrum (which are independent of $L$ ). The sensitivity of the SAR signature to variations in surface roughness parameters is evaluated by means of theoretical scattering models. For smoother geological surfaces such as most arid terrain types, single scattering is dominant, which means that the roughness parameters can be determined from SAR data using comparatively simple algorithms. Multiple scattering processes on rough surfaces such as a'a lava and variations of the local incidence angle due to large-scale terrain undulations make the retrieval of roughness parameters by means of inverse modeling much more complex. Field data of surface roughness indicate that rougher geological surfaces may be in the diffractal regime at higher radar frequencies, in which the scattering characteristics deviate significantly from the patterns observed for stationary surfaces. On the basis of surface and scattering models, recently published observations of roughness data and radar signatures from volcanic, alluvial, and arid surfaces are examined.
\end{abstract}

Index Terms - Electromagnetic scattering, geology, inverse problems, rough surfaces, synthetic aperture radar (SAR).

\section{INTRODUCTION}

$\mathbf{T}$ THE TERRAIN roughness is an important parameter in certain geological investigations. Examples include characterization and classification of lava flows, alluvial deposits, and desert surfaces. The variation and distribution of lava flow surface morphologies can be interpreted in terms of the eruption style and the emplacement history of a lava field [1]-[3]. Farr [4] and Evans et al. [5] showed that at the Cima volcanic field in the Mojave Desert, the modification of lava surface roughness by weathering and eolian deposition can be used to determine the age of the lava flows. In geological mapping of volcanic areas, it is important to distinguish between the highly fluid pahoehoe lava, which is a relatively

Manuscript received February 27, 1998; revised December 28, 1998. This work was supported by the Danish National Research Foundation.

The author is with the Danish Center for Remote Sensing, Technical University of Denmark, Lyngby, Denmark (e-mail: wd@emi.dtu.dk).

Publisher Item Identifier S 0196-2892(99)06148-3. smooth lava type with a ropy surface texture, and the slower moving a'a lava, which is characterized by a very rough, jagged, clinkery surface [6]. The distribution of a'a and pahoehoe is an indication of whether vents on volcanoes erupted with a high effusion rate (a'a) or a low effusion rate (pahoehoe) [7]. In arid and semiarid areas, the timing of alluvial deposition is tied to land surface instabilities caused by regional climate changes. Relative ages of alluvial fans or fan units are correlated with variations of the surface roughness [8]. Knowledge of the terrain morphology also is required in the derivation of the aerodynamic roughness, which is an important factor in the determination of sand and dust transport in desert areas [9]. In planetary studies, mapping of surface morphology and surface features provides important geological information [10].

In order to quantify surface roughness, different approaches have been used. Deroin et al. [11] analyzed simple field parameters such as maximum and average height of rocks and boulders in a given area and standard deviation of height. Other investigators measured surface elevation along one-dimensional profiles or on two-dimensional (2-D) grids by means of template devices, stereo photography, laser profilometers, and surveying. The acquired elevation data were then used either to determine rms-height and correlation lengths from the autocovariance function (e.g., [2], [3], [12], [13]) or to calculate spectral slopes, offsets, and related parameters from the surface roughness spectrum (e.g., [4], [13]-[17]).

In the case of unvegetated terrain, imaging radar systems such as the synthetic aperture radar (SAR) are sensitive to the electrical and the morphological properties of the terrain surface. Attempts have been made to link radar backscattering signature quantitatively to measured surface roughness (e.g., [11], [13], [15]-[17]). In the geological analyses of remote volcanic and desert regions on the Earth, as well as in investigations of surfaces of other planets, signature analysis and roughness inversion techniques applied to airand satelliteborne SAR imagery are considered useful tools in acquiring data of morphological properties.

The dielectric constant of geological surfaces is dependent on the chemical composition, the porosity, and the water content of the subsurface layer [18]. For unvegetated, dry surfaces with only a few compositional differences, changes in the dielectric properties are comparatively small, and radar signature characteristics are dominated by surface roughness properties [19]. In the analysis of radar imagery, the surface 
morphology is conveniently separated into different regimes of roughness, which, throughout this paper, are denoted as microtopography, large-scale topography, and the intermediate-scale region between these two regimes. The microtopographic regime comprises height variations and undulation lengths comparable to the radar wavelength. This range of the surface roughness spectrum determines intensity and type (single or multiple scattering) of the scattered radar signal. The backscattered intensity is also dependent on the local incidence angle of the radar beam on the surface. The local incidence angle is a function of tilt and orientation angle of surface facets, which are large compared to the radar wavelength. Hence, spatial variations of the local incidence angle are linked with the large-scale surface topography. The impact of the intermediate-scale region is not well known. It affects both the small-scale scattering characteristics and the reradiation patterns from large-scale topographic units.

In this paper, two widely used approaches to surface characterization in geological applications are examined, and the implications for the analysis of radar images are discussed. In Section II, the significance of roughness parameters that have been measured on various terrain types is assessed, based on the assumption that the surface can be modeled by either a stationary random process or by a power-law roughness spectrum. In the latter case, classical statistical parameters such as rms-height and correlation length depend upon the length of the analyzed profile [20], [21]. This has to be considered if measurements with different profile lengths are compared to each other. In Section III, the characteristics of radar signatures for different types of geological terrain are investigated. One important question, for example, asks, "Are the backscattering signatures of the various types of geological surfaces adequately described by a single-scattering process, or must multiple scattering and other phenomena such as backscattering enhancement be considered as well?" If single-scattering models are sufficient, and if the surface roughness can be regarded as stationary, inversion algorithms for roughness retrieval from radar signatures are much easier to establish. Scattering signatures of stationary surfaces are calculated utilizing the integral equation model (IEM) developed by Fung et al. [22]. Scattering from power-law surfaces is addressed on the basis of the work by Yordanov and Ivanova [23]. In this case, roughness parameters that are independent of profile length have to be used to describe the relationship between backscattering signature and surface roughness. The effect of the spatial resolution of the radar sensor and the influence of the large-scale topography on the scattering signature is discussed as well.

\section{Surface CharacteriZATION}

\section{A. The "Conventional" Approach}

The morphology of a geological surface is the result of complex formation and weathering processes. For a quantitative surface characterization, parameters have to be selected that will allow a clear discrimination between different types of morphology. The most obvious parameters are the magnitude and horizontal length scale of surface height variations. If the surface can be modeled as a stationary random Gaussian process, mean and variance of the elevation, and the autocorrelation function (which is related to the horizontal length scale of height variation) provide a complete description of the statistical surface properties. In theoretical models of rough surface scattering, it is often assumed that the surface is stationary with a Gaussian height distribution [24]. This will be termed the "conventional approach" in the following discussion. In addition, it is assumed that the mean elevation of the surface is subtracted from all height data. In this case, the autocorrelation function is identical to the autocovariance function, and the square root of the height variance is the standard deviation around zero mean.

The shape of the autocovariance function (ACF) depends on the surface characteristics. In theoretical models of radar scattering, Gaussian and exponential ACF's are widely used [25]. In several investigations of natural surfaces in which it is (implicitly or explicitly) assumed that the surface height elevation behaves like a stationary random process, it has been found that the exponential function or combinations of exponential and Gaussian functions are reasonable approximations to most of the measured ACF's [25]-[28]. Realizations of one-dimensional (1-D) surface profiles with Gaussian and exponential ACF (both with the same variance and correlation length) are shown in Fig. 1. Also included is a profile with a power-law spectrum, which is discussed in the next section. The synthetic profiles were generated closely following [29]. A terrain characterized by an exponential ACF includes relatively more small-scale roughness elements than a Gaussian correlated surface. Compared to the surface with exponential $\mathrm{ACF}$, the low-frequency roughness components of the powerlaw surface are relatively larger than the higher-frequency elements, which is reflected by the smoother appearance of the lower curve in Fig. 1.

The ACF $R(x)$ and the spectral density of surface roughness $S\left(f_{x}\right)$ are a Fourier transform pair (Wiener-Khinchine relations, see, e.g., [30])

$$
\begin{aligned}
R(x) & =\int_{0}^{\infty} S\left(f_{x}\right) \cos \left(2 \pi f_{x} x\right) d f_{x} \\
S\left(f_{x}\right) & =4 \int_{0}^{\infty} R(x) \cos \left(2 \pi f_{x} x\right) d x
\end{aligned}
$$

where $f_{x}$ is the spatial frequency and $S\left(f_{x}\right)$ is the one-sided roughness spectrum $\left(f_{x} \geq 0\right)$. For the Gaussian ACF, the pair $R(x) \leftrightarrow S\left(f_{x}\right)$ is given by

$R(x)=s^{2} \exp \left(-x^{2} / l^{2}\right) \leftrightarrow S\left(f_{x}\right)=2 \sqrt{\pi} l s^{2} \exp \left(-\pi^{2} l^{2} f_{x}^{2}\right)$

and for the exponential ACF by

$$
R(x)=s^{2} \exp (-|x| / l) \leftrightarrow S\left(f_{x}\right)=\frac{4 s^{2} l}{\left(1+4 \pi^{2} l^{2} f_{x}^{2}\right)}
$$

where $s$ is the rms-height, and $l$ is the correlation length. The spectra are depicted in Fig. 2. At large spatial frequencies $\left(l f_{x}>1\right)$, the spectrum of an exponentially correlated surface approaches a power-law spectrum of the form $1 / f_{x}^{2}$, whereas in 


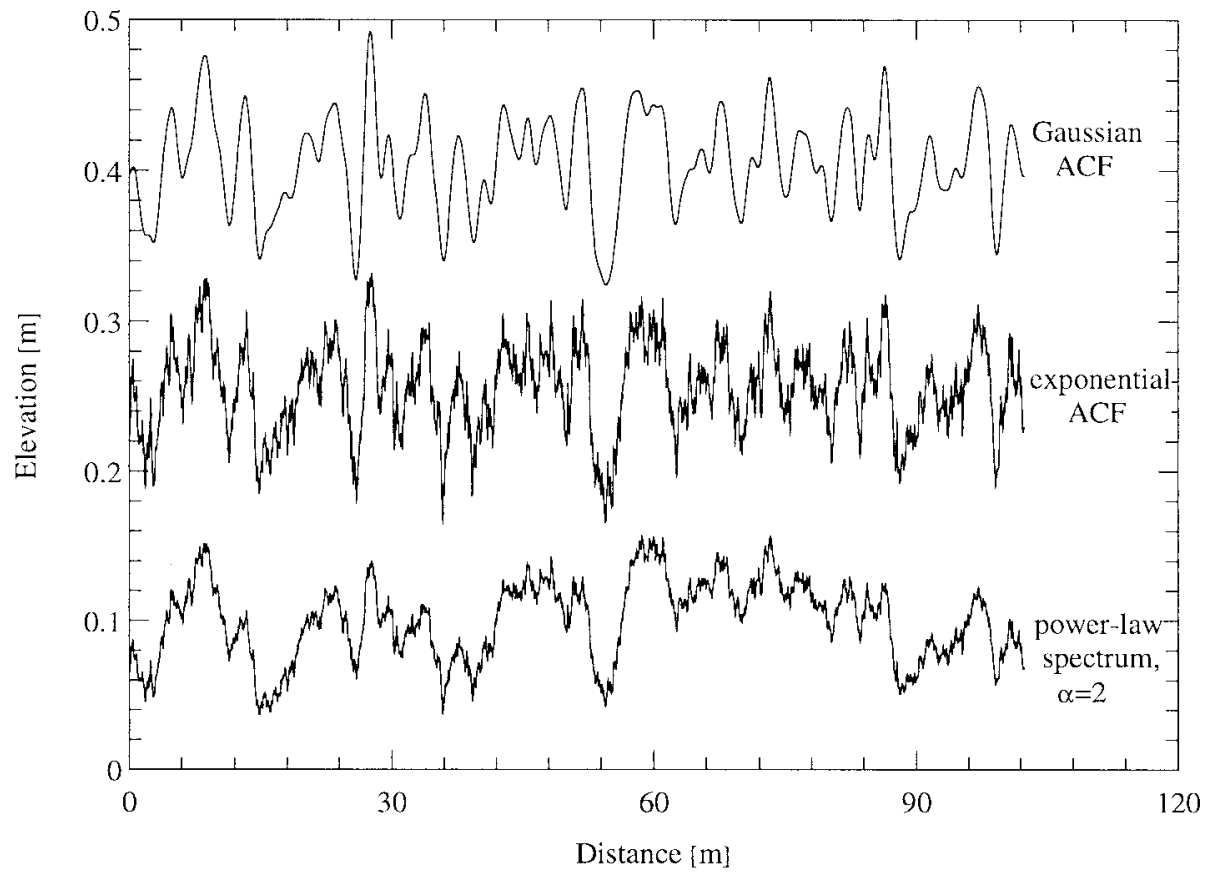

Fig. 1. Surface profiles generated on the computer. The two upper profiles are cuts of stationary random surfaces. The lower profile is from a surface with a roughness spectrum described by a large-scale cutoff power law. Profiles are offset vertically for clarity.

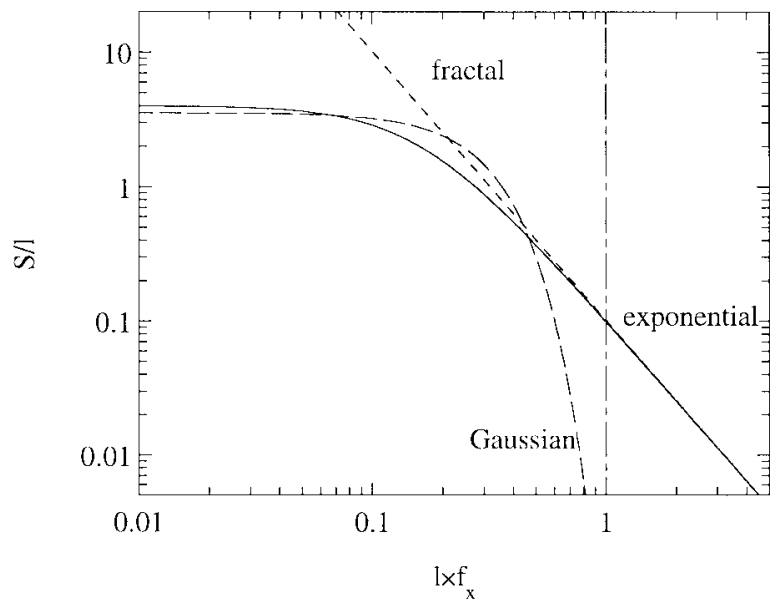

Fig. 2. Spectra of Gaussian (long-dashed line) and exponential (solid line) correlated surfaces, normalized by the correlation length $l$ versus the product of $l$ and spatial frequency $f_{x}$. At large spatial frequencies $\left(l \times f_{x}>1\right)$, the exponential spectrum approaches a fractal spectrum of the form $1 / f_{x}^{2}$. The rms-height is set to one.

the case of the Gaussian spectrum, the amplitudes of roughness elements with $l f_{x}>1$ are negligible.

A geological surface also may be characterized by its slope properties. In many cases, the rms-value of the slopes measured along a profile is used as a quantitative parameter [21]. For larger values of $s / \lambda_{\text {radar }}$ and $l / \lambda_{\text {radar }}$, where $\lambda_{\text {radar }}$ is the radar wavelength, the backscattered radar signal depends on the rms-slope $m$ rather than on the surface roughness spectrum [31]. The knowledge of the value of $m$ for a given surface is also useful in order to assess whether or not multiple scattering processes can be neglected. In the case of $1-\mathrm{D}$ profiles and for isotropic surfaces, the rms-slope can be obtained from

$$
m^{2}=-\left.\frac{d^{2} R}{d x^{2}}\right|_{x=0}=\int_{0}^{\infty} 4 \pi^{2} f_{x}^{2} S\left(f_{x}\right) d f_{x}
$$

which is the second derivative of the ACF at the origin $(x=0)$ [30]. For the Gaussian ACF, $m=\sqrt{2} s / l$. For the exponential $\mathrm{ACF}, m$ is infinite, that is, a surface with an exponential ACF does not have an rms-slope. This is also the case for power-law surfaces, which are discussed in the next section.

A fundamental feature of stationary Gaussian processes is that measurements of the standard deviation of the height and the correlation length are not dependent on the profile length (or grid size), provided that the profile length (grid size) is very large compared to the correlation length, and that the spatial resolution is sufficient [26], [32]. The requirement of a sufficiently long profile is due to the fact that mean and trend removal in the surface elevation data affect the shape of the measured ACF [33], [34]. Therefore, the question is, "How long do the profiles need to be in order to get estimates of the roughness parameters that are close enough to the 'true' (intrinsic) value?" In Fig. 3, rms-height and correlation length were determined as a function of profile length, using an expression for the correlation function of a finite sample, from which mean and trend have been removed (see [34]). An estimate of the rms-height that deviates less than five per cent from the true value can be obtained at profile lengths of about $50 l_{0}$ and larger ( $l_{0}$ here is the true correlation length). In order to get a correspondingly accurate estimate of the correlation length, the profile should be more than $200 l_{0}$ long. Similar results have been obtained recently from Monte Carlo simulations [28]. 


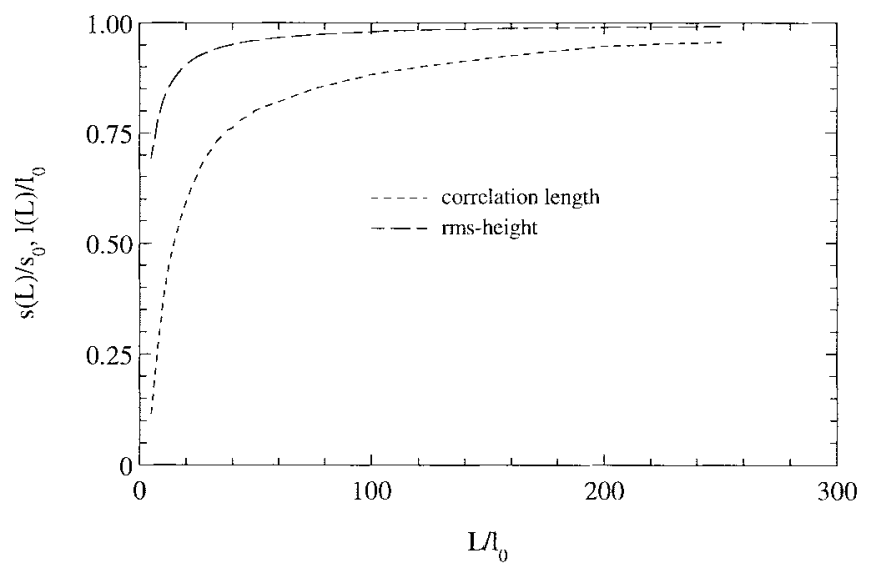

Fig. 3. RMS-heights and correlation lengths normalized by their intrinsic values $s_{0}$ and $l_{0}$, respectively, as a function of the profile length normalized by $l_{0}$. The curves were evaluated according to [34].

\section{B. Power-Law Surfaces}

In a number of studies investigating the roughness spectra of natural surfaces, it has been found that the measured spectra may be modeled reasonably well using a power law spectrum of the form

$$
S\left(f_{x}\right)=c / f_{x}^{\alpha}
$$

where $\log _{10}(c)$ is the offset, and $\alpha$ is the spectral slope, which for 1-D profiles is bounded by $1 \leq \alpha \leq 3$ [35], [36]. Surfaces with a (one-sided) power-law roughness spectrum, valid over the interval $0 \leq f_{x} \leq \infty$, are ideal random fractals. They are "self-affine," i.e., statistically indistinguishable if they are rescaled according to $h(x) \rightarrow h(r x) / \sqrt{r^{\alpha-1}}$ where $r$ is the scaling factor (e.g., [36]). Examples of fractal surfaces for different spectral slopes $\alpha$ are shown in Fig. 4. For an ideal fractal, the conventional parameter rms-height $s$, correlation length $l$, and ACF do not exist.

In many applications, surfaces are better modeled as being fractal only within a limited interval $f_{x, \min }<f_{x}<$ $f_{x, \max }$ (that is, as approximate self-affine processes). A mathematical model for this is a power law spectrum with sharp cutoffs $f_{x, \min }$ and $f_{x, \max }$. In this case, an ACF exists (e.g., [36], [37]). The shape of the ACF varies with the cutoff frequencies. That is, the shape is dependent on the roughness scales included in the analysis. The theoretical ACF of an approximate self-affine process shows an oscillatory behavior for large lags (see Fig. 5), which also is observed often in measured ACF's (see, e.g., [19]). However, this oscillatory behavior is not an unambiguous indicator of a fractal surface. Also, in the case of random surfaces, the ACF of a finite profile of length $L$ with mean and trend-removed changes sign at least twice in the interval $[0, L][33]$.

If the "approximate self affine" character of a surface is not obvious, the surface roughness might be analyzed in terms of $s$ and $l$. The important point is that rms-heights and correlation lengths evaluated from fractal roughness profiles depend on the profile length $L$ of the measurement process and do not converge to the intrinsic value for large $L$ as in the case of stationary random surfaces [20]. This is demonstrated below by analyzing the "pseudo" rms-heights and correlation lengths of surfaces with power-law spectra. In order to indicate that the roughness parameters are evaluated from a random fractal, they are written as a function of the profile length $L$. In the following discussion, only the interval $1 / L<f_{x}<\infty$ is considered, i.e., the influence of the spatial resolution of the measured profile is neglected. RMS-height and correlation length are given by [20]

$$
\begin{aligned}
s^{2}(L) & =\int_{1 / L}^{\infty} S\left(f_{x}\right) d f_{x} \\
l^{*}(L) & =\frac{1}{2 s^{4}} \int_{1 / L}^{\infty} S^{2}\left(f_{x}\right) d f_{x}
\end{aligned}
$$

where $S\left(f_{x}\right)$ again is the one-sided power spectrum. It is noted that $l^{*}$ generally does not correspond to the $e^{-1}$-correlation length $l$ used in the preceding section. For example, if the ACF is Gaussian, then $l^{*}=l \sqrt{\pi / 2}$, but for an exponential $\mathrm{ACF}, l^{*}=l$. For the purpose of studying the dependence on $L$, the definitions given in (5) and (6) are easy to handle and are therefore applied to a power-law spectrum (4), [20]

$$
\begin{aligned}
s(L) & =\left(\frac{c L^{\alpha-1}}{\alpha-1}\right)^{1 / 2} \\
l^{*}(L) & =\frac{(\alpha-1)^{2} L}{2(2 \alpha-1)}
\end{aligned}
$$

The rms-heights as functions of the profile length $L$ (assuming a constant offset) are shown for different spectral slopes in Fig. 6. Equation (7) also was used to evaluate the pseudorms-height of the power-law profile in Fig. 1. The correlation length is a linear function of the profile length $l^{*}=a L$, with $a=0.014(0.17,0.35)$ for $\alpha=1.2(2.0,2.8)$. That means, for example, that for $\alpha=2.8$, the ratio $L / l^{*}$ is only a little less than three for any selected value of $L$.

Here, only monofractal behavior was considered. That is, the surface is described by a single value for the spectral slope. Natural surfaces, however, reveal variations of the spectral slope over different bands of the spatial frequency [38]. This has to be taken into account when a large range of spatial frequencies is involved in the analysis of surface roughness.

\section{Roughness Parameters Measured on Geological Surfaces}

In Table I, roughness data from geological surfaces are listed, which have been evaluated using the conventional approach. Between the individual investigations, the profile lengths differ by up to a factor of 100 and the spatial resolution of the measurements by up to a factor of 25 . In most cases, results for rms-heights and correlation lengths are given, but an analysis of the shape of the ACF is not included. In the paper by Gaddis et al. [3], data are tabulated only for the rmsheights measured on different types of lava. However, for a number of the profiles, the ACF's are shown, from which the $e^{-1}$ correlation lengths given in Table I were determined. The roughness spectrum has been analyzed explicitly in none of the studies except [13]. It is therefore not possible to assess whether the investigated surfaces are better approximated by a power-law spectrum. 


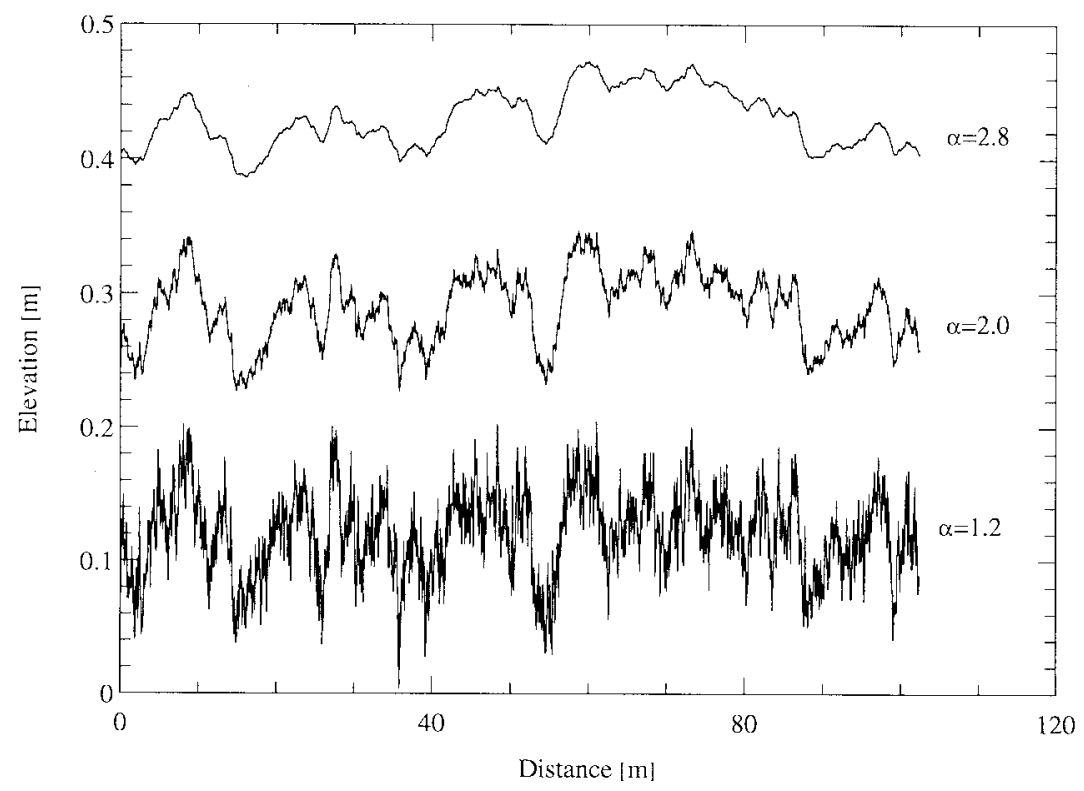

Fig. 4. Surface profiles generated on the computer, assuming roughness spectra of the form $S\left(f_{x}\right)=c / f_{x}^{\alpha}$.

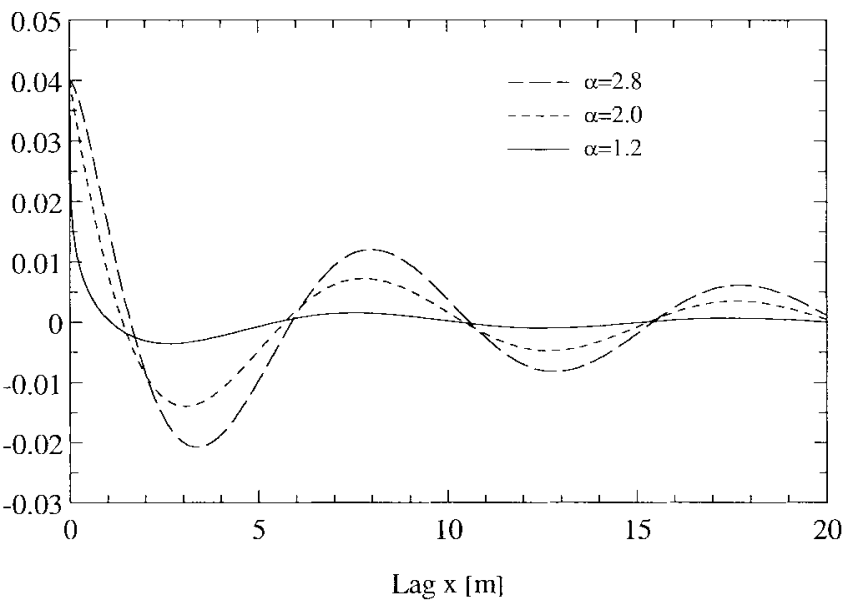

Fig. 5. Autocovariance function of surfaces with power-law spectra (sharp-cutoff model), assuming different spectral slopes $\alpha$. The curves were evaluated according to [36]. All surfaces have the same rms-height of $s=0.02 \mathrm{~m}$. The considered range of roughness components is from 0 up to $10 \mathrm{~m}$ wavelength.

In the studies by Gaddis et al. [3], Greeley et al. [12], and van Zyl et al. [13], the ratios $L / l$ are relatively small (between roughly ten and 45). This indicates either that the surface is approximately self-affine, or that the measured correlation length $l$ is considerably smaller than the intrinsic value $l_{0}$. For instance, if $L / l_{0}=10(20,40)$, then $L / l$ is $27(34,52)$ (see Fig. 3). A large value for $L / l$ is not an unambiguous indicator that a surface is stationary and $l$ is close to the intrinsic value, since for a power-law surface with a small spectral slope, the ratio $L / l$ is also comparatively large (for example, for $\alpha=1.2, L / l>70)$. However, at very large ratios $(L / l$ roughly $>200)$, a stationary random process may be a reasonable surface approximation.

Campbell et al. [2] analyzed 20-m-long surface-elevation profiles of lava flows, which were highpass filtered in order to

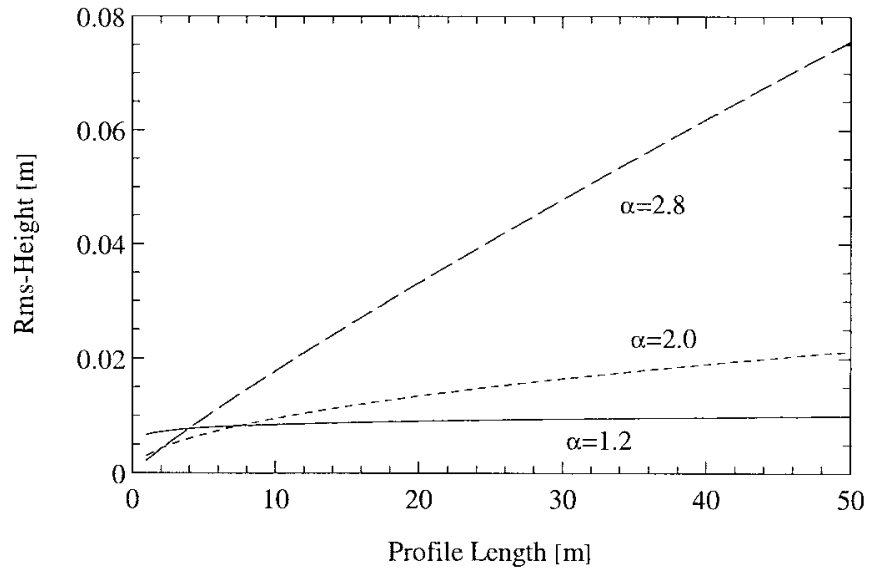

Fig. 6. Rms-height of a profile with power-law spectrum $S\left(f_{x}\right)=c / f_{x}^{\alpha}$ for different values of the spectral slope $\alpha$ as a function of profile length $L$. The offset is $\log _{10}(c)=-5.0$.

suppress undulations much longer than the radar wavelength $\lambda_{\text {radar. }}$ The reason is that the roughness parameters are dominated by the large surface undulations, but in the analysis of radar scattering, the knowledge of the small-scale roughness parameters is essential. The ratio $L / l$ of the filtered profiles lies between 170 and 205, which indicates that they may be approximated by a conventional stationary random process, and that the measured roughness parameters are a good estimate of the intrinsic values. However, the question is whether the filtered profiles include all surface roughness components that the radar waves interact with. This point is addressed in more detail in Section III-E. The roughness data given in [39] were derived from profiles with a spatial resolution of $25 \mathrm{~cm}$. For applications in radar data analysis, surface profiles need to be sampled with a horizontal resolution of $\Delta x \leq 0.1 \lambda_{\text {radar }}$ [24, ch. 11]. Hence, for frequency bands between X- and Pband, which are considered in the discussions in the following 
TABLE I

Examples of the Conventional Approach of Surface Roughness Characterization: Determination of rms-Height $(s)$ and Correlation Length $(l)$

\begin{tabular}{|c|c|c|}
\hline Reference, Site & Surface Type $(s[\mathrm{~cm}], l[\mathrm{~cm}])$ & Additional Information \\
\hline $\begin{array}{l}\text { Campbell et al. (1989) } \\
\text { lava flows, Craters of the } \\
\text { Moon, Idaho }\end{array}$ & $\begin{array}{l}\mathrm{a}^{\prime} \mathrm{a}(10.0,10) \\
\text { shelly pahochoe }(5.0,12)\end{array}$ & $\begin{array}{l}20.5 \text { m long profiles (combined from shorter } \\
\text { segments, segment length not given) with a } \\
\text { spatial resolution of } 2 \mathrm{~cm} \text {. Profiles were } \\
\text { filtered to suppress wavelengths }>1 \mathrm{~m} \text {. }\end{array}$ \\
\hline $\begin{array}{l}\text { Gaddis } \text { et al. (1990) } \\
\text { December } 1974 \text { lava flow, } \\
\text { Kilauca Volcano, Hawaii }\end{array}$ & $\begin{array}{l}\text { ropy pahoehoc }(5.3,48 ; 9.8,43)^{1,2} \\
\text { slab pahochoc }(12.2,57 ; 16.6,69)^{1,2} \\
\text { ball a'a }(20.6,37 ; 22.0,38)^{1,2} \\
\text { ball a'a }(17.7,18 ; 21.9,23)^{1,2} \\
\text { ball a'a }(12.7,20 ; 24.4,88)^{1,2}\end{array}$ & $\begin{array}{l}\text { 9-m profiles (combined from } 1.8 \mathrm{~m} \text { profiles) } \\
\text { with a spatial resolution of } 2.54 \mathrm{~cm} \text {; profiles } \\
\text { reveal complicated structures (steep flanks, } \\
\text { sharp edges); some of the along-and across- } \\
\text { flow mcasurements indicatc anisotropic } \\
\text { roughness }\end{array}$ \\
\hline $\begin{array}{l}\text { Greeley et al. (1991) } \\
\text { alluvial fan units in Death } \\
\text { valley }\end{array}$ & $\begin{array}{l}\text { gravel to cobble sized clasts with a } \\
\text { sandy matrix } \\
(6.2,212 ; 3.3,174)^{3} \\
(0.97,12.5)^{4} \\
\text { gravel to cobble sized clasts with } \\
\text { scattered boulders } \\
(6.6,284 ; 2.6,162)^{3} \\
(0.76,3.7)^{4} \\
\text { mud flow surface with alternating } \\
\text { strips of sand and gravel } \\
(7.7,117 ; 3.9,147)^{3} \\
(1.5,11.2)^{4} \\
\text { sand and gravel surface (reg) } \\
(0.56,12)^{4}\end{array}$ & $\begin{array}{l}\text { 24-m profiles (combined from 2-m profiles) } \\
\text { with a spatial resolution of } 1 \mathrm{~cm} \text {; laser } \\
\text { profiles of } 1.2 \mathrm{~m} \text { in length with } 2-3 \mathrm{~mm} \\
\text { spatial resolution; all large scale } \\
\text { measurements reveal indications of } \\
\text { anisotropy }\end{array}$ \\
\hline $\begin{array}{l}\text { van Zyl et al. (1991) } \\
\text { different sites in Mojave } \\
\text { Desert, California }\end{array}$ & $\begin{array}{l}\text { playa }(0.63,36) \\
\text { cobbles }(0.95,47) \\
\text { pahoehoe }(2.97,102)\end{array}$ & $\begin{array}{l}\text { sites were } 10 \text { by } 10 \mathrm{~m}^{2} \text { in size; } \\
\text { microtopographic maps and profiles were } \\
\text { generated from helicopter borne stereo } \\
\text { photography }\end{array}$ \\
\hline $\begin{array}{l}\text { Campbell and Garvin } \\
\text { (1993) } \\
1982 \text { lava flow, Kilauea } \\
\text { Caldera, Hawaii }\end{array}$ & $\begin{array}{l}\text { ponded surface }(7.7,350)^{5} \\
\text { channelized pahochoe }(17.9,650)^{5} \\
\text { moderately rough a'a }(26.9,275)^{5}\end{array}$ & $\begin{array}{l}100-120 \mathrm{~m} \text { long profiles with a spatial } \\
\text { resolution of } 25 \mathrm{~cm}\end{array}$ \\
\hline $\begin{array}{l}\text { Deroin } \text { et al. (1997) } \\
\text { different geological units } \\
\text { of an arid area in the } \\
\text { Western Sahara }\end{array}$ & $\begin{array}{l}\text { reg }(0.07,2.2)^{6} \\
\text { reg with boulders }(1.9,26.7)^{7}\end{array}$ & $\begin{array}{l}\text { height measurements of individual elements } \\
\text { within the area (presumably no regular } \\
\text { spacing); arcal paramctcrs werc determined } \\
\text { from photographs; rms-heights were } \\
\text { evaluated from theoretical profiles which } \\
\text { were generated from the height and areal } \\
\text { parameters }\end{array}$ \\
\hline \multicolumn{3}{|c|}{$\begin{array}{l}{ }^{1} \text { Correlation lengths are not given explicitly, they were determined from the ACFs shown in Fig. } 6 \text { of Gaddis et al. } \\
\text { (1990) }\end{array}$} \\
\hline \multicolumn{3}{|c|}{${ }^{2}$ Measurements were carried out along (first $s, l$-pair) and across flow (second $s, l$ pair) } \\
\hline \multicolumn{3}{|c|}{${ }^{3}$ large-scale measurements S-N (first $s, l$-pair) and W-E (second $s, l$ pair) } \\
\hline \multicolumn{3}{|c|}{${ }^{4}$ laser measurements $1.2 \mathrm{~m}$ profiles } \\
\hline \multicolumn{3}{|c|}{${ }^{5}$ the values of $s$ and $l$ are for unfiltered profiles } \\
\hline \multicolumn{3}{|c|}{${ }^{6}$ rms-height and average distance between rocks, minimum values measured } \\
\hline${ }^{7}$ rms-height and average & tance between rocks, maximun & \\
\hline
\end{tabular}

sections, a value of $\Delta x=25 \mathrm{~cm}$ is too large. The measurement strategy of Deroin et al. [11] does not provide estimates of the roughness parameters needed in the conventional approach. They defined a set of descriptive parameters easily measured and closely related to the geological characterization in the field. Since their standard deviation of measured rock heights and the average distance of rocks are more or less equivalent (but not directly comparable) to $s$ and $l$ used above, their data also are listed in Table I.
Examples of the power-law approach can be found in Table II. In most of the references, the roughness spectra were computed as functions of wavenumber $k=2 \pi f_{x}$ rather than the spatial frequency $f_{x}$. The relationship between the offsets derived from $S_{k}(k)=C_{k} / k^{\alpha}$ and $S\left(f_{x}\right)=c / f_{x}^{\alpha}$ is

$$
\log _{10}(c)=\log _{10}\left(C_{k}\right)-\alpha \log _{10}(2 \pi) \text {. }
$$

In Table II, the offset valid in the spatial frequency domain $\log _{10}(c)$ is given. A relative lack of small-scale roughness is 
TABLE II

Power-LaW Approach: Roughness Characterized by Spectral Slope $\alpha$ ANd Offset $\log (c)$

\begin{tabular}{|c|c|c|}
\hline Reference, Site & Surfacc Type $(\alpha, \log (c))$ & Additional Information \\
\hline $\begin{array}{l}\text { van Zyl et al. (1991) } \\
\text { Mojave Desert, California }\end{array}$ & $\begin{array}{l}\text { playa }(2.34,-4.6)^{2} \\
\text { cobbles }(2.46,-5.2)^{2} \\
\text { pahoehoe }(2.57,-4.1)^{2}\end{array}$ & $\begin{array}{l}\text { stereo photography, spectra evaluated from } 5.12 \\
\text { m profiles with } 1 \mathrm{~cm} \text { spatial resolution }\end{array}$ \\
\hline $\begin{array}{l}\text { Farr (1992) } \\
\text { Cima Volcanic Fiield, } \\
\text { Mojave Desert, California }\end{array}$ & $\begin{array}{l}\text { lava flows } \\
1.99<\alpha<2.46^{1} \\
-4.2<\log (c)<-2.5^{1.2}\end{array}$ & $\begin{array}{l}\text { stereo photography, data are given for } 9 \\
\text { different flows, number of averaged spectra } \\
\text { varies between } 3 \text { and } 250 \text {, spectra evaluated } \\
\text { from } 5.12 \mathrm{~m} \text { profiles with } 1 \mathrm{~cm} \text { spatial } \\
\text { resolution }\end{array}$ \\
\hline $\begin{array}{l}\text { Austin and England } \\
\text { (1993) } \\
\text { Mount St. Helens, } \\
\text { Washington }\end{array}$ & $\begin{array}{l}\text { debris flow }(2.34,-3.5) \\
\text { debris flow }(2.31,-3.4) \\
\text { sedimented plain with scattcred } \\
\text { hummocky debris mounds } \\
(2.51,-3.3)\end{array}$ & $\begin{array}{l}\text { laser profiler and surveying instrument, } \\
\text { roughness spectra were evaluated using Capon's } \\
\text { estimator, spectral fits include wavclengths } \\
\text { between } 2 \mathrm{~cm} \text { and } 20 \mathrm{~m}\end{array}$ \\
\hline $\begin{array}{l}\text { Weeks et al. (1996) } \\
\text { Death Valley, California }\end{array}$ & $\begin{array}{l}\text { alluvial fans } \\
2.29<\alpha<2.71^{1} \\
-3.8<\log (\mathrm{c})<-3.4^{1,2}\end{array}$ & $\begin{array}{l}\text { stereo photography, data are given for } 11 \\
\text { different sites, spectral fits include wavelengths } \\
\text { between } 4 \mathrm{~mm} \text { and } 5 \mathrm{~m}\end{array}$ \\
\hline
\end{tabular}

1 Minimum and maximum values are given.

2 Offsets given in the reference are for spectra in the wavenumber domain, here they are calculated for a spectrum in the spatial frequency domain

characterized by a steeper slope $\alpha$ and a larger roughness over the whole spectral range corresponds to a smaller negative value of $\log _{10}(c)$. Between the references listed in Table II, there are differences in the range of spatial frequencies over which spectral slopes and offsets are calculated. Some of the spectra reveal a varying slope as a function of spatial frequency (e.g., [13, Fig. 2] and [4, Fig. 5]). This implies that a single value of $\alpha$, evaluated for a wide-frequency band, may differ considerably from the values of smaller-frequency bands.

In Weeks et al. [16], several rms-heights are given together with spectral slopes and offsets. The rms-heights were obtained from profiles with lengths of $1 \mathrm{~m}$ (R. Weeks, personal communication). It is thus possible to compute $\alpha$ and $\log _{10}(c)$ using (7). A comparison of the rms-height evaluated directly from the profiles (using the conventional approach) and the theoretical value according to (7) is shown in Fig. 7. In general, the deviations between theoretical and measured values are relatively large, which may indicate that the monofractal power-law approach is more or less oversimplifying the real surface characteristics. It also has to be considered that Weeks et al. [16] used shorter profiles for evaluating the rms-height ( $L=1 \mathrm{~m}$ ) than for fitting a power-law function to the measured spectra $(L=5 \mathrm{~m})$. The theoretical correlation lengths according to (8) vary from 23 to $33 \mathrm{~cm}$ for the data given in [16].

\section{RADAR SignATURES}

\section{A. Surface Scatter Modeling (Conventional Approach)}

The numerical simulations of interactions between radar waves and geological terrain now presented focus on the scattering at the terrain surface, and any volume contributions are neglected. The latter might arise if a larger portion of the

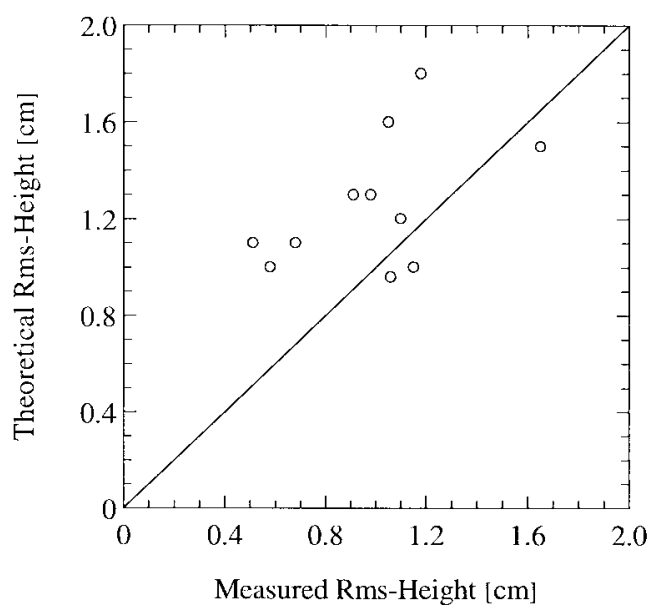

Fig. 7. Comparison of rms-heights measured in the field and estimated from spectral slope and offset (7).

incident radar beam intensity is transmitted into the subsurface layer and then scattered by volume inhomogeneities. Furthermore, the effects of the large-scale topography will not be considered throughout this section, as they will be discussed in Section III-E. Throughout Sections III-A-C, the conventional approach of surface characterization is used, i.e., a stationary random surface with Gaussian height distribution is assumed. A theoretical approach widely used in the analysis of scattering from random surfaces is the integral equation model (IEM) developed by Fung et al. [22] and described in detail in [25]. In its most general form, it comprises a wide range of surface roughness scales. For practical applications, however, approximations that are restricted to narrower roughness regimes must be used. For small to moderate roughness (that is, for $k s<2$ ), 
the backscattering coefficient $\sigma^{0}$ is

$$
\begin{aligned}
& \sigma_{p q}^{0}(\varepsilon, k s, k l, \theta)= \\
& \frac{k^{2} l^{2}}{2} \exp \left(-2 k_{z}^{2} s^{2}\right) \sum_{n=1}^{\infty}\left\{\left(2 k_{z} s\right)^{2 n} \exp \left(-2 k_{z}^{2} s^{2}\right)\left|f_{p q}\right|^{2}\right. \\
& \quad+2^{n}\left(k_{z} s\right)^{2 n} \exp \left(-k_{z}^{2} s^{2}\right) \\
& \quad \cdot \operatorname{Re}\left[f_{p q}^{*}\left(F_{p q}\left(-k_{x}, 0\right)+F_{p q}\left(k_{x}, 0\right)\right)\right] \\
& \left.\quad+\frac{1}{4}\left(k_{z} s\right)^{2 n}\left|F_{p q}\left(-k_{x}, 0\right)+F_{p q}\left(k_{x}, 0\right)\right|^{2}\right\} \frac{\tilde{W}\left(k_{x} l\right)}{n !}
\end{aligned}
$$

where

$$
\begin{array}{ll}
p & \text { incident polarization; } \\
q & \text { scattered polarization; } \\
\varepsilon & \text { dielectric constant of the surface; } \\
k & \text { radar wavenumber; } \\
s & \text { rms-height; } \\
l & \text { correlation length; } \\
k_{x}=k \sin \theta, & \text { wavenumber components in } x \text { - } \\
k_{z}=k \cos \theta & \text { and } z \text {-direction; } \\
\theta & \text { incidence angle; } \\
f_{p q}, F_{p q} & \text { field coefficient; } \\
F_{p q} & \text { complementary field coefficient. }
\end{array}
$$

The field coefficients and the complementary field coefficients at polarization $p q$ are given in $[25, \mathrm{p} .64] . \tilde{W}$ is related to the correlation length by

$$
\tilde{W}\left(k_{x} l\right)=\frac{1}{2 n} \exp \left(-\frac{\left(2 k_{x} l\right)^{2}}{4 n}\right)
$$

if the ACF of the surface is Gaussian and by

$$
\tilde{W}\left(k_{x} l\right)=\frac{1}{n^{2}}\left[1+\left(\frac{2 k_{x} l}{n}\right)^{2}\right]^{-1.5}
$$

if the surface roughness is characterized by an exponential ACF. The polarization of the radar signal considered here is linear (horizontal " $\mathrm{H}$ " or vertical "V"). Note that $s$ and $l$ are the intrinsic values. Since the backscattering coefficient is a function of the products $k s$ and $k l$, the choice of the radar frequency determines whether a surface appears smooth or rough to the radar. The IEM is derived by separating the electromagnetic field on the surface in a Kirchhoff and a complementary term [25, pp. 164-175]. In (10), the first term is the Kirchhoff field squared, the third term is the complementary field squared, and the second term is the cross product between these two fields.

In the Kirchhoff approximation, the basic assumption is that the electromagnetic field at a point on the surface can be computed as if the incident wave is impinging on an infinite plane tangent to that point. This requires that the surface correlation length $l$ and the average radius of surface curvature need to be larger than the radar wavelength $\lambda_{\text {radar }}[24$, p. 949]. Thorsos [40] showed that for surfaces with Gaussian roughness spectra, a large value of the ratio $l / \lambda_{\text {radar }}$ is sufficient. In the IEM, the influence of smaller surface undulations on the scattering process is taken into account by the complementary term.

In the derivation of (10), it is assumed that multiple scattering processes do not contribute significantly to the backscattered signal and hence can be ignored. This means that the rms-slope has to be smaller than 0.4 [25, p. 231]. For single scattering, the cross-polarized returns ( $\mathrm{HV}$ and $\mathrm{VH}$ ) are zero. The field coefficients depend on the Fresnel reflection coefficients.

For rougher surfaces (with $k_{z} s>1.6$ and $l>\lambda_{\text {radar }}$ ), the IEM is identical to the geometrical optics (GO) model [24, ch. 12]. This model is based on the assumption that the backscattered signal is proportional to the occurrence probability of surface patches, which reflect the incident wave specularly into the direction of observation

$$
\sigma^{0}(\varepsilon, m, \theta)=|R(0)|^{2} \frac{\exp \left(-\frac{\tan ^{2} \theta}{2 m^{2}}\right)}{2 m^{2} \cos ^{4} \theta} .
$$

Here, $m$ is the rms-surface slope and $R(0)$ is the Fresnel reflection coefficient at normal incidence angle. Multiple scattering is not considered. Therefore, $m$ should be smaller than 0.4. The model does not include depolarization effects. Since the Fresnel reflection coefficient is evaluated at $\theta=$ 0 , the backscattering coefficients at vertical and horizontal polarization are equal. Equations (10) and (12) are valid for a monostatic radar system (i.e., transmitting and receiving antenna can be regarded as located at the same position).

As can be seen in the examples given above, there are certain mathematical restrictions in analytical scattering models that limit the range of the surface roughness values to which the models can be applied. Hence, different analytical approximations must be utilized for theoretical studies of scattering from geological surfaces in order to cover the whole range of typical roughness values observed for a certain surface type. This complicates the direct application of analytical models in roughness inversion algorithms. Nevertheless, the analytical approximations are very useful in basic investigations, as is shown below.

\section{B. Sensitivity of Backscattering Signatures to Surface Roughness}

In order to analyze the radar sensitivity to the roughness of different geological surfaces, the backscattering coefficients at $\mathrm{VV}$-polarization were computed for different combinations of $k s$ and $k l$, using the IEM and GO models. The results shown are for a Gaussian correlated surface, using the incidence angle of $23^{\circ}$ of the SAR's onboard the European remote sensing satellites ERS-1 and ERS-2 (Fig. 8) and likewise are for an exponential correlated surface illuminated at $23^{\circ}$, $35^{\circ}$ (the incidence angle of the SAR onboard the Japanese satellite JERS-1), and $50^{\circ}$ (which is included in the incidence angle range covered by many airborne SAR measurements) [Fig. 9(a)-(c)].

The comparison between Figs. 8 and 9(a) suggests that for Gaussian correlated surfaces, the sensitivity of the backscattering coefficient to changes in the rms-height $s$ is larger than 


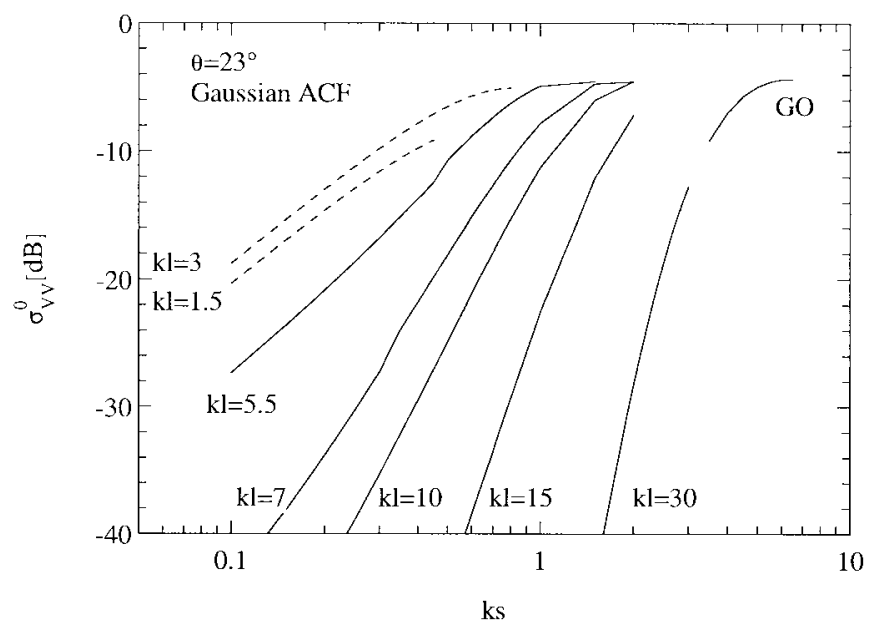

Fig. 8. Sensitivity of the backscattering coefficient at VV polarization to changes in rms-surface height $s$ at different correlation lengths $l$ for a Gaussian surface autocovariance function. The incidence angle $\theta$ of the radar waves is $23^{\circ}$ and $k$ is the radar wavenumber. The dielectric constant of the surface is 4.5 .

that for exponential correlated surfaces. The backscattering coefficient saturates at certain values of $k s$ dependent on the correlation length $l$. The larger $l$, the larger the value of $s$ becomes, for which $\sigma^{\circ}$ saturates. In scatterometer measurements of soil surfaces, Oh et al. [27] observed that $\sigma_{\mathrm{VV}}^{\circ}$ becomes insensitive to surface roughness for $k s>2.0$ and $k l \approx 17$, which compares well with the model results. For a fixed rms-height, the backscattered radar intensity decreases with increasing correlation length (Fig. 10). The curves depicted in Fig. 10 indicate that the radar sensitivity to correlation length becomes rather small for $k l>30$ (that is, for correlation lengths $l>5 \lambda_{\text {radar }}$ ). The sensitivity of $\sigma_{\mathrm{VV}}^{\circ}$ to correlation length $l$ is smaller than that to rms-height $s$. The sensitivity of the backscattering coefficient to $s$ does not differ noticeably between different incidence angles, as can be seen in Fig 9. The magnitude of $\sigma_{\mathrm{VV}}^{o}$ decreases with increasing incidence angle, and the decrease is larger for larger values of $k l$. Finally, it is noted that variations of the dielectric constant cause vertical shifts of the $\sigma^{o}$-curves, i.e., the magnitude of the backscattered intensity is decreased or increased, but the first derivative of the curve, $d \sigma^{\circ} / d s$, remains substantially unchanged (not shown).

During field work, the length of roughness profiles may have to be chosen comparatively short, so that possibly, the data of $s$ and $l$ may not be intrinsic values (Section II-A). If this is not considered in scattering simulations, how much does the backscattering coefficient computed for "nonintrinsic" values of $s$ and $l$ differ from the one obtained for the intrinsic values? In order to answer this question, several intrinsic pairs $\left(k s_{0}, k l_{0}\right)$ were selected, and for each pair, the decrease of $k s$ and $k l$ with decreasing profile length $L$ (down to $L / l_{0}=10$ ) was determined on the basis of the curves shown in Fig. 3. At the minimum profile length of $L / l_{0}=10$, the "measured" values are $0.82 k s_{0}$ and $0.36 k l_{0}$. The resulting backscattering coefficients are depicted in Fig. 11. For example, if $k s_{0}=2.0$, the variations of $\sigma^{0}$ are less than $2 \mathrm{~dB}$. If $k s_{0}=0.4$ and $k l_{0}=20$, the variations are larger than $3 \mathrm{~dB}$. To be

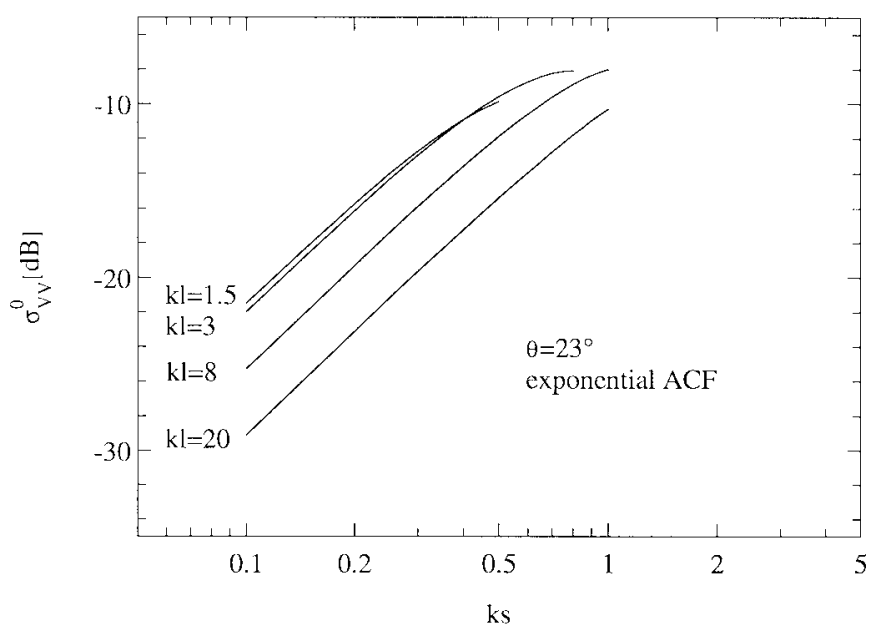

(a)

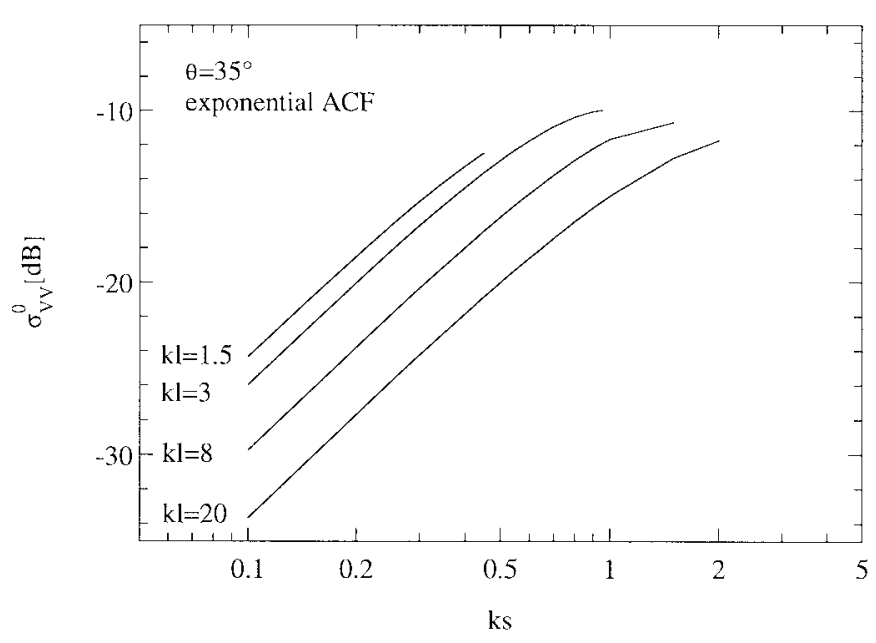

(b)

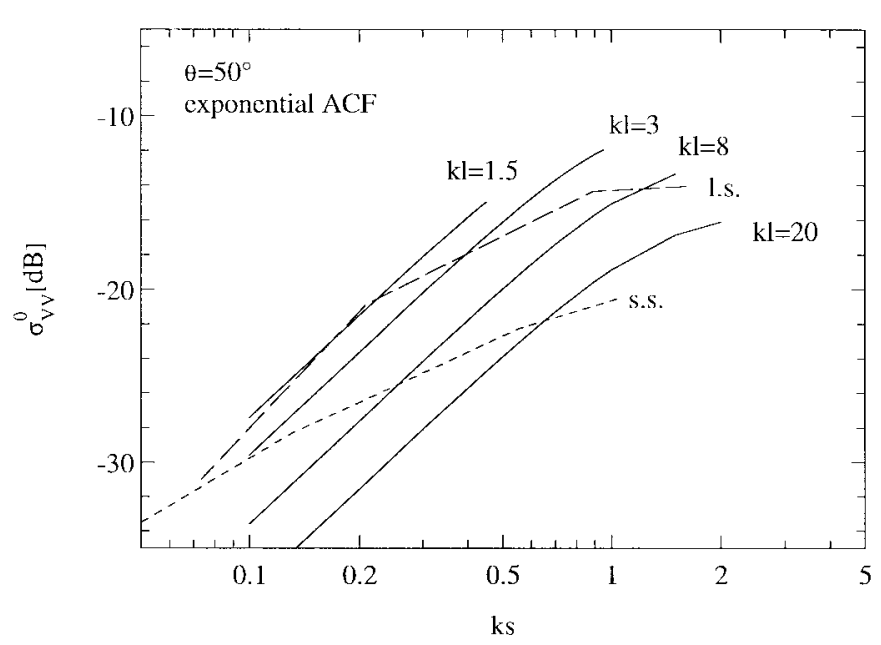

(c)

Fig. 9. Sensitivity of the backscattering coefficient at VV polarization to changes in rms-surface height $s$ at different correlation lengths $l$ for an exponential surface autocovariance function and a dielectric constant of 4.5. The incidence angle $\theta$ of the radar waves is (a) $23^{\circ}$, (b) $35^{\circ}$, and (c) $50^{\circ}$, respectively. The dashed curves in (c) are computed for constant values of $s$ and $l$ and varying radar wavenumber $k$. The values for the small-slope ("s.s.") curve are $s=0.5 \mathrm{~cm}$ and $l=15 \mathrm{~cm}$. The values for the large-slope ("1.s.") curve are $s=0.8 \mathrm{~cm}$ and $l=5 \mathrm{~cm}$. 


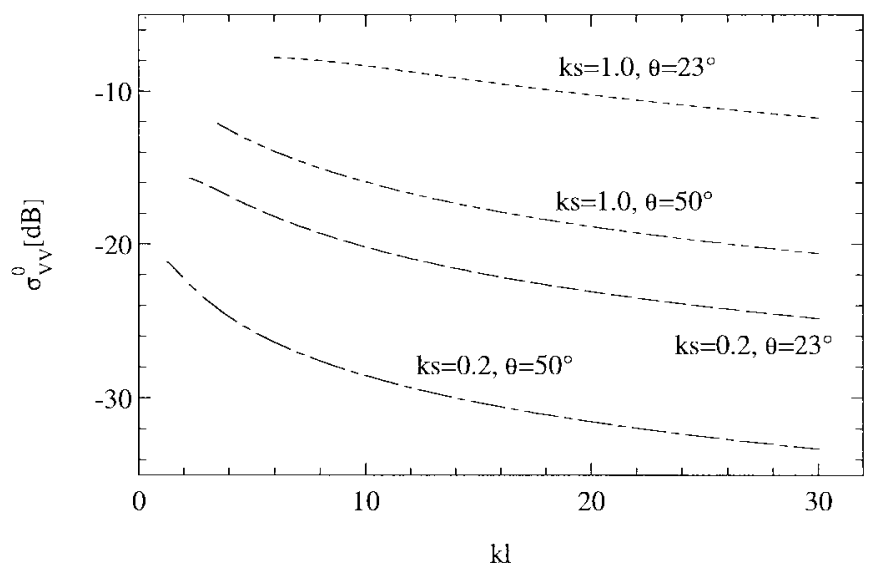

Fig. 10. Sensitivity of the backscattering coefficient to variations in the correlation length $l$, shown for different values of $k s$ and different incidence angles $k$ (radar wavenumber) and $s$ (rms-height). The dielectric constant of the surface is 4.5 .

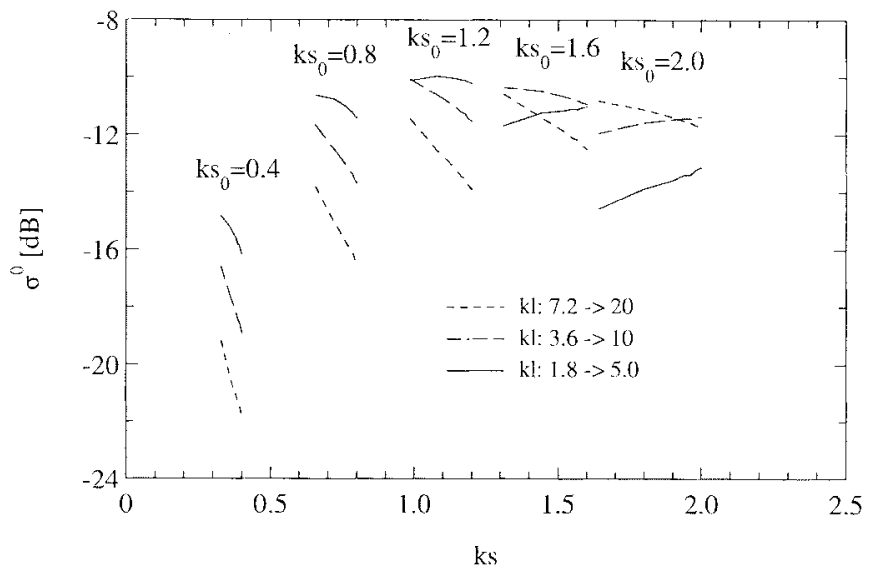

Fig. 11. Backscattering coefficients for different pairs of $k s_{0}$ and $k l_{0}$ and the corresponding variations $k s$ and $k l$ as a function of profile length $L$. Here, $s_{0}$ and $l_{0}$ are the intrinsic values of rms-height and correlation length, respectively. The dielectric constant of the surface is 4.5 . The pairs $k s, k l$ were taken from Fig. 3. The left end of the curves is for $s$ and $l$ at a profile length of $L / l_{0}=10$. The right end is for the intrinsic parameters.

more specific, in the latter case, if the roughness parameters (measured at a profile length of $L / l_{0}=10$ ) are used in a scattering model, the predicted $\sigma^{0}$ is more than $3 \mathrm{~dB}$ larger than the measured value of $\sigma^{0}$. Thus, in the case of highly accurate radar measurements, the consideration of the profile length is important for the validation of scattering models and the development of inversion algorithms.

So far, it has been assumed that the wavenumber $k$ is a constant. However, with regard to inversion, it is also interesting to analyze the case when the surface parameters $s$ and $l$ are fixed, and $k$ (i.e., the radar frequency) varies. If the backscattering coefficients measured at different frequencies are available, ambiguities in algorithms for roughness inversion are diminished or even can be avoided. Two examples for $\sigma^{0}$ as a function of frequency are depicted in Fig. 9(c) (dashed curves). Backscattering coefficients were evaluated at $\mathrm{P}-, \mathrm{L}-$, $\mathrm{C}$-, and X-band for a large-slope $(s / l=0.16)$ and a smallslope $(s / l=0.03)$ surface. The selected values of $s(0.8 / 0.5$ $\mathrm{cm})$ and $l(5 / 15 \mathrm{~cm})$ are close to the roughness parameters reported in [12] for $1.2 \mathrm{~m}$ profiles on alluvial fans (Table I). For $k s \leq 0.9$, the sensitivity of the backscattering coefficient to changes in frequency is smaller in the case of the smooth surface than in the case of the rough surface. For the latter, the backscattered intensity at larger values of $k s$ is almost identical at $\mathrm{C}$-band $(k s=0.9)$ and $\mathrm{X}$-band $(k s=1.7)$, which indicates that $\sigma_{\mathrm{VV}}^{o}$ is at or close to the saturation level at X-band. The robustness and accuracy of an inversion scheme is optimal if the sensitivity to surface roughness is large for the selected frequencies. Hence, rougher surfaces should be imaged at lower frequencies, and the different radar frequencies should be distributed within a narrower frequency interval. Smoother surfaces should be imaged using higher frequencies (in order to increase the SNR of the radar sensor), and using radar frequencies spread over a wider frequency range.

The results presented above are essentially valid at $\mathrm{HH}-$ polarization also, although the sensitivity to surface roughness at small values of $s$ and $l$ is slightly larger than at VVpolarization (e.g., [25]). Cross-polarized responses cannot be explained by single-scattering processes. Effects of anisotropic surface roughness, which may be important for lava flows, were not discussed explicitly, but these effects also can be dealt with using the IEM or GO model. Only surfaces with a Gaussian height distribution were considered. Therefore, a remaining question is, "Is the backscattering behavior of surfaces with non-Gaussian height statistics different?" This question is addressed, for instance, by Eom and Fung [41] and Wu et al. [42]. They found that the effect of different height distributions on the noncoherent scattering characteristics is almost negligible in the case of smooth surfaces but increases at larger rms-heights.

\section{Scattering Processes on Lava Flows and Alluvial Fans}

Until now, the focus was on surface roughness values, which are within the validity regime of the single-scattering approximation of the IEM or the GO. The span of roughness data measured on natural surfaces, however, is much wider. This will be considered in the following discussion.

In order to assess the contribution of different scattering mechanisms from geologic surfaces as a function of roughness, the surface data listed in Table I are depicted in $k l-k s$ diagrams [Fig. 12(a)-(d)] for P-, L-, C-, and X-band. The radar bands were selected considering currently operational airborne and spaceborne SAR sensors. Also shown in Fig. 12 are the regions of validity for the single-scattering IEM (IEM-SS) and the GO model. The Fraunhofer criterion (see [24, p. 827]) was used to evaluate the rms-height for which the surface can be regarded as "radar-smooth" (dependent on the incidence angle). Such surfaces are characterized by very low intensities in a radar image, which may be at or close to the noise level of the sensor.

The upper limits for the IEM-SS and the GO model are given by $m<0.4$. In Fig. 12, it is assumed that the surface is isotropic, and that $s=m l / \sqrt{2}$ (oblique short-dashed lines) also can be used as an estimate of the upper limit for surfaces with ACF's different from a Gaussian function. The IEM-SS can be applied for $k s \leq 0.2$. A limit for the maximum value 
P-Band

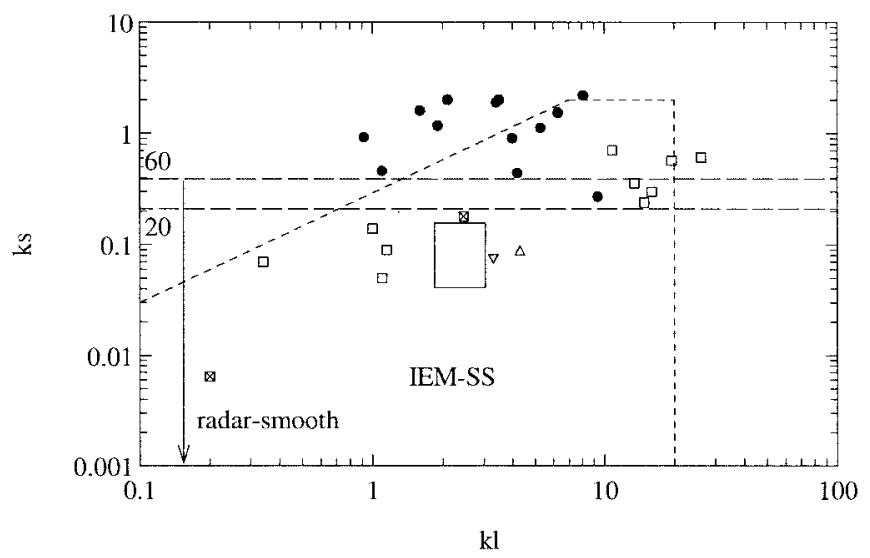

(a)

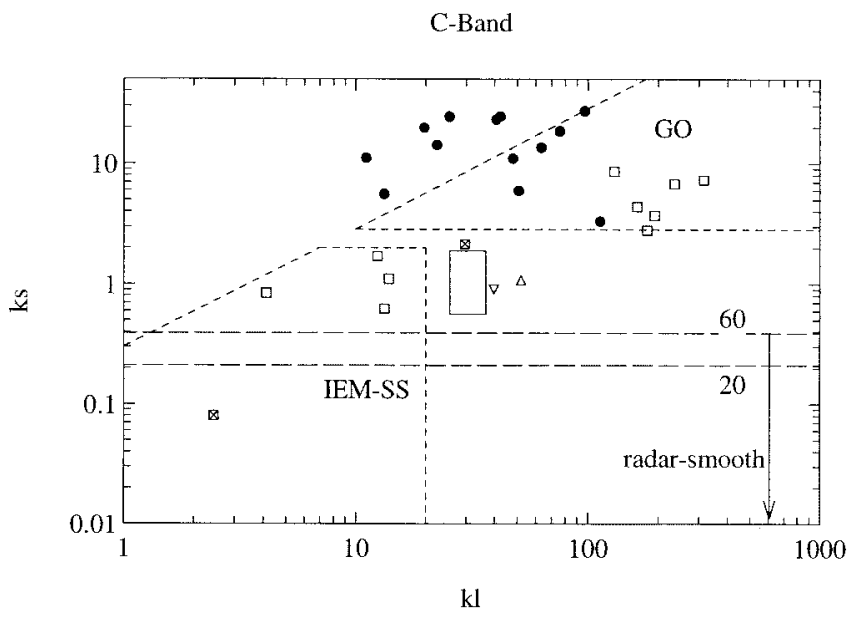

(c)

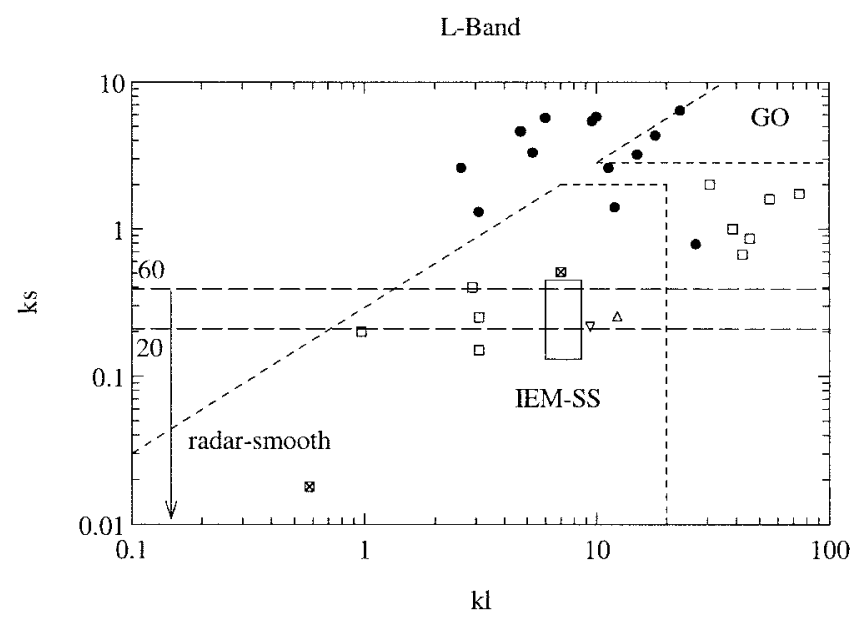

(b)

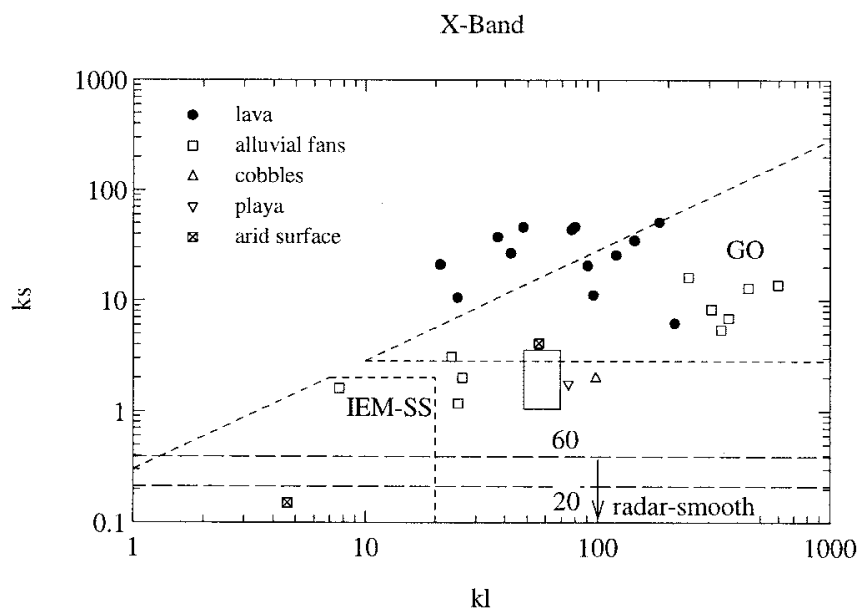

(d)

Fig. 12. Measured roughness parameters of different geological surfaces in a $k s-k l$ diagram for different radar bands, using the data of the references listed in Table I. Here, $k$ is wavenumber, $s$ is rms-height, and $l$ is the correlation length. The boundaries marked by the short-dashed lines indicate the regions in $k s-k l$ space in which the different surface scattering models can be applied. IEM-SS is the single-scattering approximation of the integral equation model, and GO is the geometrical optics approximation. For values of ks below the long-dashed lines, the surface can be regarded as "radar-smooth." These lines are shown for radar incidence angles of $20^{\circ}$ and $60^{\circ}$, respectively. The large rectangle indicates the range of $k s-k l$ values of alluvial fans measured by [16] on $1 \mathrm{~m}$-long profiles. For further explanations, see Section III-C.

of $k l$ is more difficult to establish. The range of validity of the IEM-SS examined by Fung et al. [22] extends to $k l=20$. This value was used as a rough upper limit in the $k l-k s$ diagrams. However, the IEM-SS also may be valid for larger values of $k l$ as long as it is considered that the antenna footprint of the radar has to be at least twice as large as the surface correlation length [43]. If $k l=20$, the dimensions of the antenna footprint at P-band should be larger than $4.3 \mathrm{~m}$ (the possible spatial resolution of recent operational airborne sensors is better than $4 \mathrm{~m}$ ). The minimum value of $k s$ for the GO model (which is evaluated using $k_{z} \cos \theta>1.6$, see Section III-A) at an incidence angle of $60^{\circ}$ is 2.8 (horizontal short-dashed lines), and at an incidence angle of $20^{\circ}$, it is 1.6 (not shown in the diagram).

The values of $s$ and $l$, listed in Table I and shown in Fig. 12 (normalized by the radar wavelength), were evaluated from roughness measurements assuming a stationary (nonfractal) random surface model. As was discussed in Section II, this assumption either may not be adequate, or the profile length may be too short, so that the roughness data are smaller than the intrinsic values. For stationary surfaces and for power-law surfaces with a large-scale cutoff, the ratio of $s / l$ decreases with increasing profile length $L$, and in the case of a stationary surface, it decreases until the intrinsic value is reached. Therefore, single data in the $k l-k s$ diagram may have to be shifted in order to represent the intrinsic values or the roughness scales the radar waves interact with. For most of the parameters listed in Table I, there is no information about the roughness spectra, and it is assumed that the data cluster define a more or less representative range of roughness values of a certain surface type.

Considering the number of data points for different terrain types, the following discussion will be restricted to lava flows (filled circles) and alluvial fans (open squares). Additional roughness data of alluvial fans were determined from the spectral slopes and offsets given in [16] by computing the 
correlation lengths $l^{*}$ for a profile length of $1 \mathrm{~m}$, using (8). Together with the rms-heights listed in [16], these correlation lengths were used to define a range of roughness indicated by the large rectangle.

Many of the lava surfaces reveal a roughness from which complex scattering processes such as multiple scattering or backscatter enhancement are to be expected. The IEM was recently extended to include multiple scattering (and in this form is denoted as IEMM) and was compared to radar measurements from Gaussian correlated, perfectly conducting surfaces [44]. The authors emphasize that model simulations with the IEMM are "lengthy and time consuming." For high-slope rough surfaces $(m>0.5)$, a model based on a higherorder Kirchhoff approximation (including shadowing) was developed by Ishimaru and coworkers (e.g., [45], [46]). As predicted by this model and observed in experimental studies, backscatter enhancement takes place when the rms-height of the rough surface is of the order of a wavelength and the rms-slope is close to unity. Recently, Hsieh and Fung [47] reported that backscatter enhancement is also included in the IEMM. They explain the enhancement by single spots on the surface which may act as corner reflectors, causing a strong reflection in the backscattering direction. The utilization of theoretical models such as the IEMM and the higher-order Kirchhoff model for the inversions of lava surface roughness from radar measurements must at present be regarded as very difficult in view of the complexity of the theories.

In the case of alluvial fans, multiple scattering is much smaller or even negligible, and the rms-slope is comparatively small in general. At longer wavelengths (P-band and partly L-band), alluvial fans may be "radar-smooth" and are thus characterized by very low returns in the radar images. For roughness mapping, the frequencies from $\mathrm{X}$ - to L-band that are best suited are those corresponding to the shuttle imaging radar (SIR-C) configuration. In principle, inversion schemes based on the single-scattering IEM and the GO are applicable. Their performance depends on how close the mathematical model approximates the real surface.

At higher radar frequencies, many surfaces reveal roughness values that fall into the part of the $k s-k l$ diagram covered by the GO model. However, (12) cannot be applied in case these surfaces are characterized by an exponential ACF that does not have an rms-slope. Even if one considers that the radar is insensitive to high frequency roughness components with horizontal scales much smaller than the radar wavelength, the effect of small-scale undulations comparable to the radar wavelength cannot be neglected, i.e., ideal specular facets do not exist on such a surface. A simple analytic solution for this case is not available.

\section{Power-Law Surfaces}

The main difference between scattering from a conventional, single scale surface and a fractal surface is that in the latter case, the radar waves interact with different roughness scales as the wavelength is varied [48]. In the case of the IEM, a solution for surfaces with power-law spectra is not available at present. Yordanov and Ivanova [23] have studied scattering from perfectly conducting surfaces characterized by a powerlaw spectrum with and without large-scale cutoff. They used the Kirchhoff approximation (neglecting multiple scattering) and assumed that the incident e.m. waves were vertically polarized. Their results are the basis for a qualitative assessment of scattering characteristics from geological surfaces.

The computational details on which the following discussion is based are given in the Appendix. In Fig. 13, measured roughness parameters from the references listed in Table II are plotted in a $\gamma-\log _{10}\left(c_{2}\right)$ diagram. Here, $\gamma$ and $\log _{10}\left(c_{2}\right)$ are spectral slope and offset characterizing the (2-D) roughness spectrum of an isotropic surface. They can be evaluated from slope and offset of the 1-D spectrum. For fractal surfaces, the curves of the backscattering coefficient $\sigma^{0}$ as a function of the incidence angle $\theta$ are of variable shape and may in certain cases deviate significantly from the patterns observed for stationary surfaces [23]. Dependent on spectral slope and offset, the function $\sigma^{0}(\theta)$ reveals a behavior typical for stationary surfaces (i.e., $\sigma^{0}$ decreases with increasing $\theta$ ), has a maximum at angles $>0^{\circ}$, or even increases with increasing $\theta$ until $\theta=90^{\circ}$. The two latter cases are denoted as the diffractal regime of scattering. In Fig. 13, lines are drawn to mark the border between nonfractal scattering behavior (to the left) and the diffractal regime (to the right). These lines were determined on the basis of the results shown in [23, Figs. 3 and 5]. At X-band, for example, several roughness data of lava flows are within the diffractal regime. This has to be considered in the interpretation of radar data as a function of the local incidence angle. It is emphasized that the separation of nonfractal and diffractal regime in Fig. 13 has to be regarded as a rough estimate, since examples in [23] are given only for two values of $\gamma\left(\gamma_{1}=3.4\right.$, and $\left.\gamma_{2}=2.6\right)$ and perfectly conducting surfaces. Further detailed theoretical simulations have to be carried out for dielectric surfaces and for different combinations of spectral slopes and offsets in order to determine the regime of diffractal scattering more precisely.

\section{E. Influence of Large-Scale Topography}

In the preceding sections, the radar characteristics of plane surfaces with a superimposed small-scale roughness are discussed. Here, the notation "small-scale" means that variations of the local incidence angle within the antenna footprint or the resolution cell of the radar sensor can be neglected. In the case of airborne and satelliteborne SAR imaging, however, the effects of the large-scale topography and of the intermediatescale region have to be considered as well. Surface undulations with wavelengths at least twice as large as the resolution cell cause signature variations from cell to cell due to changes of the local incidence angles. The local incidence angle for each resolution cell can be estimated from a digital elevation model (DEM) [49] or from SAR interferograms [50]. A SAR scene usually covers several types of scattering media, which reveal different functional dependencies of the scattering intensity on the incidence angle, so that the removal of intensity variations due to the topography is difficult and in certain cases not appropriate. Instead, a map of the local incidence angle can 


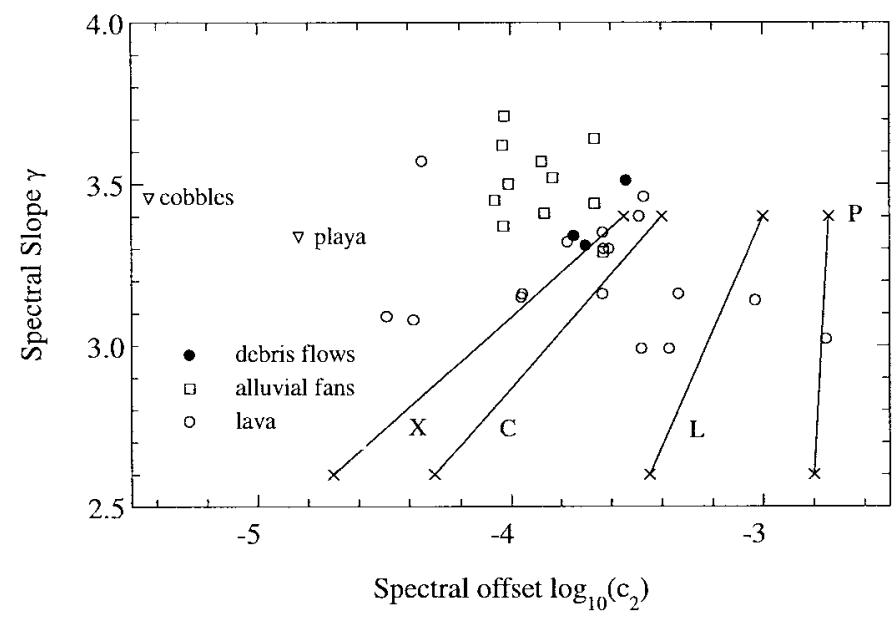

Fig. 13. Measured roughness parameters of different geological surfaces using the power-law approach. The values are taken from the references listed in Table II and are plotted for the case of an isotropic surface. Computational details are given in the appendix. To the right of the lines marked by the frequency bands "P," "L," "C," and "X," the scattering is in the diffractal regime, respectively. The end points of the lines marked by a cross are values taken from [23]. The lines are linear interpolations.

be generated and then used in the geologic interpretation of a given SAR scene.

If the resolution cell is very large compared to the radar wavelength, simulations of the radar signature may have to consider large-scale variations of the local incidence angle inside the cell. A possible solution is to approximate the surface by plane facets, which are small in terms of the spatial resolution of the radar but large compared to the radar wavelength (e.g., [51]; [52, pp. 1830-1841]). For each facet, the backscattering coefficient is evaluated using an appropriate electromagnetic model such as the IEM. The returns of all facets inside a resolution cell are added incoherently, taking into account the reradiation pattern and the orientation of individual facets [24, pp. 837-841]. Note that surface tilt and orientation angles have to be considered when the return of a single facet is evaluated since, for example, a horizontally polarized radar wave will appear locally as a horizontal and a vertical incident wave [24, pp. 966-973], which means that the backscattered signal includes a depolarized component. For lower radar frequencies, the required dimension of a facet may result in an inadequate approximation of the large-scale surface topography. Simulations of the radar return of nonplanar facets are possible (taking into account the changes in the reradiation pattern), though more complex. The determination of the backscattering coefficient of individual facets, however, becomes very difficult, since the radar incidence angle, which has to be used in the evaluation of the Fresnel reflection coefficients, is varying spatially over the facet area [51].

The facet model, as it is explained above, is a useful concept in examining the modulation of radar signatures by the largescale topography. However, its applicability must be assessed from case to case, dependent on radar frequency, spatial sensor resolution, effective correlation length of the microtopography, and length scales of large-scale slope variations. If a resolution cell contains many facets of different orientations and with varying roughness, the individual properties of each facet are not visible in the radar signature because of the incoherent summation over all facet returns. The correlation between in situ surface parameters of individual facets and the backscattered signal is then very low. Hence, the retrieval of roughness parameters from radar images acquired over rugged terrain with a coarse spatial resolution may be meaningless in the extreme case.

In Section II, it was not considered explicitly that the radar "distinguishes" between microtopography, intermediatescale roughness, and large-scale topography. In case a largescale topography exists, high-pass filtering is necessary in order to determine the roughness parameters characterizing the microtopography (or the small-scale undulations on a facet). Because of the filtering procedure, the roughness parameters vary as a function of the cutoff wavelength, independent of the type of surface (stationary or fractal). This leads us to the question: "At what spatial frequency does the microtopographic regime as a function of radar frequency end?" Unfortunately, there is no clear answer. In the facet model, the effective facet size is not only a function of radar wavelength but also is dependent on the large-scale surface slope and curvature as well as on the radar incidence angle. This has been demonstrated for small-scale ripples on long, sinusoidal ocean waves [52, pp. 1707-1715], resulting in facet lengths from roughly ten to more than 100 times the radar wavelength. On the ocean surface, the radar interacts with small-scale waves, which are proportional to the radar wavelength (as in the case of fractal surfaces). In order to get a better knowledge of the transition region between largescale topography and microtopography, further theoretical and experimental studies are needed.

\section{F. Interpretation of Recent Observations}

Gaddis [19] investigated radar signatures measured at the Pisgah lava field, using like- and crosspolarized airborne SAR data at P-, L-, and C-band, with a spatial resolution of $10 \mathrm{~m}$. She found that the different lava textures can be discriminated very well at L-band, whereas at P-band, the signature variations between the lava types are smaller. At Cband, almost all lava units are characterized by high returns, i.e., the backscattered signal seems to be close to or at the saturation level. She concluded that cross-polarized data at L-band are most useful for separation of Pisgah lava flows. Her observations compare qualitatively with the result of Section III-B, which shows that in the case of rougher, largeslope surfaces, the sensitivity of the backscattering coefficient $\sigma^{\circ}$-to-surface roughness is large at lower frequencies but only within a comparatively narrow radar frequency range [Fig. 9(c)]. However, it has to be considered that the roughness values typically observed for lava flows are larger than the values used in the theoretical analysis presented in Section III-B. The Pisgah lava field reveals rms-heights from 3 to $15 \mathrm{~cm}$ (correlation and profile length were not given in [19]). The fact that P- and L-band cross-polarized data allow a better discrimination of lava textures than copolarized data (see [15]) emphasizes the importance of multiple scattering contributions and also may indicate the influence of large-scale topographic 
elements within a radar resolution cell, since tilted surface facets also cause a depolarization of the incident radar waves.

Weeks et al. [17] used C- and L-band SAR data from the SIR-C mission in order to study the correlation between $\sigma^{\circ}$ (averaged over an area of about $60 \times 60 \mathrm{~m}^{2}$ ) and roughness parameters obtained from alluvial fan units in Death Valley. Different roughness inversion methods were tested as well. They found a good correlation between $\sigma^{\circ}$ and spectral offsets (slightly better at C-band than at L-band) and a weaker correlation with rms-height (better at L-band than at C-band). Spectral offsets were computed including surface components up to wavelengths of $5 \mathrm{~m}$. The measured rms-heights (profile length $1 \mathrm{~m}$ ) varied (with one exception) between $s=0.5 \mathrm{~cm}$ and $s=1.2 \mathrm{~cm}(0.6<k s<1.3$ at C-band, and $0.1<k s<$ 0.3 at L-band). On the basis of the spectral parameters given in their paper, estimated values for $k l$ are between 25-37 at C-band and between 6-9 at L-band (see Section II-C). These values correspond to the small-slope case in Fig. 9(c). Hence, useful information can be expected using multifrequency radar sensors covering a relatively large frequency interval. The comparatively weak correlation between $\sigma^{\circ}$ and rms-height shows that the influence of the correlation length cannot be neglected, and/or that the roughness scales the radar waves interact with are not well characterized at a profile length of $1 \mathrm{~m}$. The spectral offsets that include longer roughness scales show a better correlation with $\sigma^{\circ}$, but since the backscattered intensity is a function of spectral slope as well, the correlation coefficient between $\sigma^{\circ}$ and spectral offset is considerably smaller than one. Weeks et al. [17] point out that the inversion of roughness parameters was hampered by intermediate-scale roughness effects, variations of dielectric surface properties, subsurface scattering, and/or influence of vegetation. This indicates that the presently achievable spatial resolution of spaceborne SAR sensors may not be sufficient for the retrieval of roughness parameters in terrain with a complex topography.

Greeley et al. [9] combined roughness and backscattering data (the latter obtained by airborne SAR at C-, L-, and Pband) from lava fields and alluvial fans in order to study the correlations between $\sigma^{\circ}$, rms-heights, and aerodynamic roughness (Figs. 8, 11, and 12 in their paper). For smooth surfaces, the backscattering coefficients at all bands are sensitive to roughness, whereas for lava, the results are in line with the observations by Gaddis [19]. An increase of aerodynamic roughness $z_{0}$ is only weakly correlated with an increase of rms-height $s$. The correlation between $\sigma^{\circ}$ and $s$ is modest and better at L- and P-band than at C-band. At C-band, the backscattering coefficient saturates at larger rms-heights $(k s>2)$. A saturation of $\sigma^{\circ}$ also is observed as a function of $z_{0}$. The value of $z_{0}$ at which the saturation level is reached is smaller at C-band than at L- and P-band. This indicates that larger surface roughness elements that affect the wind flux are not "seen" by the radar, and that larger radar wavelengths are preferable in order to map $z_{0}$. On the other hand, longer waves (L- and P-band) penetrate deeper into the layer below the surface (in the case of dry sand, from a few tens of centimeters up to a few meters [53]) and hence, may be scattered by subsurface structures. This leads to a decrease in the correlation between $\sigma^{\circ}$ and $z_{0}$.
Using ERS-1 data from a flat, arid zone in the western Sahara, Deroin et al. [11] found a good (nonlinear) correlation between backscattering coefficient on the one hand and maximum height of roughness elements or rms-heights on the other hand. Here, $k s$ varied between 0.03-2.15. The surprisingly clear relationship between $\sigma^{\circ}$ and $s$ is a consequence of the close correlation between $s$ and $l$ [54].

\section{CONCLUSIONS}

In the first part of this paper, two stochastic surface models, widely used in the analysis of geomorphologic data, were discussed. In the first approach, it is assumed that the surface can be modeled as a stationary random process. In the second approach, the surface roughness spectrum is described by a power-law. In the former case, rms-height and correlation length are intrinsic surface parameters, whereas in the latter case, they depend on the length of the roughness profiles from which they are determined. Hence, as part of a surface parameter estimation, rms-heights $s$ and correlation lengths $l$ should be tested for their sensitivity to profile length $L$. However, for stationary random surfaces, it also must be considered that because of mean and trend removal during data processing, $s$ and $l$ increase as a function of profile length $L$ until they approximate their intrinsic values $s_{0}$ and $l_{0}$, respectively. This point is reached at about $50 l_{0}$ for $s$ and at about $200 l_{0}$ for $l$. The dependence of rms-heights and correlation lengths on the profiling length has to be taken into account when roughness measurements in the field are linked with radar data. Power-law surfaces are better characterized by the spectral slope and offset or related parameters that are independent of the profile length. In case the spectral slope $\alpha$ varies as a function of spatial frequency $f_{x}$, the estimation of roughness parameters has to be carried out over intervals of $f_{x}$ with a constant value of $\alpha$.

The second part of the paper dealt with radar signature analysis of geological surfaces and roughness inversion. For a flat, stationary random surface without large-scale topography, it was shown that smoother surfaces are optimally mapped using different frequencies distributed over a relatively broad frequency interval within the range of L- to X-band. Over rougher surfaces, the radar frequencies should be selected from a narrower frequency interval within the range of $\mathrm{P}$ to $\mathrm{S}$-band. The backscattered signal saturates at a certain rmsheight, which depends on the ratio $s / l$ and the radar frequency. Measured roughness data from lava flows, alluvial deposits, and arid surfaces are listed in Tables I and II. Lava surfaces are characterized by comparatively large rms-slopes. In particular, multiple scattering contributions to the radar return cannot be neglected for the rougher lava types (a'a). Alluvial fans and arid terrain reveal smaller rms-slopes, and single-scattering is dominant, which simplifies the construction of inversion algorithms. The roughness data of each of the investigated geological units are distributed over the validity regions of different scattering models.

A power-law spectrum with a large-scale cutoff may be a better representation of certain geological surfaces (as roughness measurements indicate). In this case, the scattering char- 
acteristics may deviate significantly from conventional surface scattering, depending on the roughness parameters and the radar frequency. Until now, modeling simulations and experimental studies of scattering from surfaces with power-law spectra did not cover the same broad range of different roughness classes as those for stationary random surfaces. Further investigations of diffractal scattering are of great interest in order to understand and interpret radar signatures from rougher geological surfaces such as, for example, a'a lava.

The radar is sensitive only to a limited range of the roughness spectrum covering the small-scale surface components with spatial scales on the order of the radar wavelength. Hence, the ideal situation for roughness inversion from radar data is a flat terrain on which the horizontal dimensions of roughness elements are considerably smaller than the radar resolution cell. In several cases, large-scale surface undulations may be present. The large-scale topography is defined as the regime of the surface roughness spectrum, which is recognized by the radar as a variation of the local incidence angle over individual surface facets of dimensions much larger than the radar wavelength. If the spatial resolution of the radar sensor is relatively large, so that one resolution cell contains several surface facets of different orientations, a meaningful roughness inversion becomes much more complex or even may not be possible. Roughness profiles with contributions from largescale undulations may have to be highpass filtered for radar signature analysis. A general valid criterion for the choice of the filter cutoff frequency as a function of radar wavelength and surface characteristics has not been established yet and should be investigated in future theoretical and experimental work.

\section{APPENDIX}

The backscattering coefficients in [23] are evaluated for the case of isotropic surfaces as functions of fractal dimension $D$ and topothesy $\tau$. The latter represents the horizontal distance over which chords joining points on the surface have an rms slope equal to one radian (e.g., [55]). In order to link the scattering characteristics discussed in [23] with the roughness data listed in Table II, the following equations are helpful. First, one needs to relate spectral slope and offset evaluated from 1-D profiles on isotropic surfaces to their 2-D equivalents. For an isotropic surface, the power-law spectrum is

$$
S_{2}\left(f_{x}, f_{y}\right)=S_{2}\left(f_{r}\right)=c_{2} / f_{r}^{\gamma}
$$

and the radial spatial frequency $f_{r}=\left(f_{x}^{2}+f_{y}^{2}\right)^{1 / 2}$. The parameters $c_{2}$ and $\gamma$ can be obtained from the parameters of the 1-D spectrum, (4), by [32]

$$
\gamma=\alpha+1 ; \quad c_{2}=\frac{\Gamma(\gamma / 2)}{\sqrt{\pi} \Gamma\left(\frac{\gamma-1}{2}\right)} c
$$

where $\Gamma$ is the gamma function. Second, relationships between $D, \tau_{2}$, and $\gamma, c_{2}$ are required. Note that the definition of the topothesy is not consistent between different references. The fractal dimension $D$, as used in [23], is related to the spectral slope by

$$
D_{2}=(8-\gamma) / 2
$$

which is the expression for the 2-D case. The parameter $c_{2}$ as a function of the topothesy $\tau_{2}$ as given in [23] is

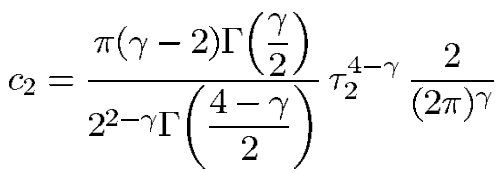

where a factor of $2 /(2 \pi)^{\gamma}$ is considered because a two-sided power-law spectrum in the wavenumber domain is used in [23].

\section{ACKNOWLEDGMENT}

The author would like to thank T. Farr and O. Yordanov for helpful discussions. H. Haack and H. Skriver are acknowledged for their fruitful comments and suggestions to the paper.

\section{REFERENCES}

[1] R. Greeley and L. Martel, "Radar observations of basaltic lava flows, craters of the Moon, Idaho," Int. J. Remote Sensing, vol. 9, no. 1, pp. 1071-1085, 1988.

[2] B. A. Campbell, S. H. Zisk, and P. J. Mouginis-Mark, "A quad-pol radar scattering model for use in remote sensing of lava flow morphology," Remote Sens. Environ., vol. 30, no. 3, pp. 227-237, 1989.

[3] L. R. Gaddis, P. J. Mouginis-Mark, and J. N. Hayashi, "Lava flow surface textures: SIR-B radar image texture, field observations, and terrain measurements," Photogramm. Eng. Remote Sensing, vol. 56, pp. 211-224, Feb. 1990.

[4] T. G. Farr, "Microtopographic evolution of lava flows at Cima Volcanic Field, Mojave Desert, CA,” J. Geophys. Res., vol. 97, no. B11, pp. 15171-15179, 1992.

[5] D. L. Evans, T. G. Farr, and J. van Zyl, "Estimates of surface roughness derived from synthetic aperture radar (SAR) data," IEEE Trans. Geosci. Remote Sensing, vol. 30, pp. 382-389, Mar. 1992.

[6] M. E. MacKay and P. J. Mouginis-Mark, "The effect of varying acquisition parameters on the interpretation of SIR-C radar data: The Virunga volcanic chain," Remote Sens. Environ., vol. 59, no. 2, pp. 321-336, 1997

[7] P. J. Mouginis-Mark, "Preliminary observations of volcanoes with the SIR-C radar," IEEE Trans. Geosci. Remote Sensing, vol. 33, pp. 934-941, July 1995.

[8] T. G. Farr and O. A. Chadwick, "Geomorphic processes and remote sensing signatures of alluvial fans in the Kun Lun mountains, China," J. Geophys. Res., vol. 101, no. E10, pp. 23 091-23 100, 1996.

[9] R. Greeley, D. G. Blumberg, A. R. Dobrovolskis, L. R. Gaddis, J. D Iversen, N. Lancaster, K. R. Rasmussen, R. S. Saunders, S. D. Wall, and B. R. White, "Potential transport of windblown sand: Influence of surface roughness and assessment with radar data," in Desert Aeolian Processes, V. P. Tchakerian, Ed. London: Chapman \& Hall, 1995, pp. 75-99.

[10] J. P. Ford, J. J. Plaut, C. M. Weitz, T. G. Farr, D. A. Senske, E R. Stoffan, G. Michaels, and T. J. Parker, "Guide to Magellan image interpretation," National Aeronautics and Space Administration (NASA) and Jet Propulsion Laboratory (JPL), Pasadena, CA, JPL Publ. 93-24, 1993, p. 148.

[11] J. P. Deroin, A. Company, and A. Simonin, "An empirical model for interpreting the relationship between backscattering and arid land surface roughness as seen with the SAR," IEEE Trans. Geosci. Remote Sensing, vol. 35, pp. 86-92, Jan. 1997.

[12] R. Greeley, A. Dobrovolskis, L. Gaddis, J. Iversen, N. Lancaster, R. Leach, K. Rasmussen, S. Saunders, J. van Zyl, S. Wall, B. White, and H. Zebker, "Radar-Aeolian roughness project," Nasa Contractor Rep. 4378, 1991.

[13] J. J. van Zyl, C. F. Burnette, and T. Farr, "Inference of surface power spectra from inversion of multifrequency polarimetric radar data," Geophys. Res. Lett., vol. 18, no. 9, pp. 1787-1790, 1991. 
[14] R. T. Austin and A. W. England, "Multi-scale roughness spectra of Mount St. Helens debris flows," Geophys. Res. Lett., vol. 20, no. 15, pp. 1603-1606, 1993.

[15] B. A. Campbell and M. K. Shepard, "Lava flow surface roughness and depolarized radar scattering," J. Geophys. Res., vol. 101, no. E8, pp. $18941-18951,1996$.

[16] R. J. Weeks, M. Smith, K. Pak, W. H. Li, A. Gillespie, and B. Gustafson, "Surface roughness, radar backscatter, and visible and near infrared reflectance in Death Valley, California," J. Geophys. Res., vol. 101, no. E10, pp. 23 077-23 090, 1996.

[17] R. J. Weeks, M. Smith, K. Pak, and A. Gillespie, "Inversion of SIR-C and AIRSAR data for the roughness of geological surfaces," Remote Sens. Environ., vol. 59, no. 2, pp. 383-396, 1997.

[18] F. T. Ulaby, T. H. Bengal, M. C. Dobson, J. R. East, J. B. Garvin, and D. L. Evans, "Microwave dielectric properties of dry rocks," IEEE Trans. Geosci. Remote Sensing, vol. 28, pp. 325-336, May 1990.

[19] L. R. Gaddis, "Lava flow characterization at Pisgah volcanic field, California, with multiparameter imaging radar," Geol. Soc. Am. Bull., vol. 104, pp. 695-703, June 1992.

[20] E. L. Church, "Fractal surface finish," Appl. Opt., vol. 27, no. 8, pp. 1518-1526, 1988.

[21] M. K. Shepard, R. A. Brackett, and R. E. Arvidson, "Self-affine (fractal) topography: Surface parameterization and radar scattering," J. Geophys. Res., vol. 100, no. E6, pp. 11709-11718, 1995.

[22] A. K. Fung, Z. Li, and K. S. Chen, "Backscattering from a randomly rough dielectric surface," IEEE Trans. Geosci. Remote Sensing, vol. 30, pp. 356-369, Mar. 1992.

[23] O. I. Yordanov and K. Ivanova, "Kirchhoff diffractals," J. Phys. A: Math. Gen., vol. 27, no. 17, pp. 5979-5993, 1994.

[24] F. T. Ulaby, R. K. Moore, and A. K. Fung, Microwave Remote Sensing, vol. 2. Reading, MA: Addison-Wesley, 1982.

[25] A. K. Fung, Microwave Scattering and Emission Models and Their Applications. Norwood, MA: Artech House, 1994.

[26] W. Dierking, A. Carlström, and L. M. H. Ulander, "The effect of inhomogeneous roughness on radar backscattering from slightly deformed sea ice," IEEE Trans. Geosci. Remote Sensing, vol. 35, pp. 147-159, Jan. 1997.

[27] Y. Oh, K. Sarabandi, and F. T. Ulaby, "An empirical model and an inversion technique for radar scattering from bare soil surfaces," IEEE Trans. Geosci. Remote Sensing, vol. 30, pp. 370-381, Mar. 1992.

[28] Y. Oh and Y. C. Kay, "Conditions for precise measurements of soil surface roughness," IEEE Trans. Geosci. Remote Sensing, vol. 36, pp. 691-695, Mar. 1998.

[29] D. Saupe, "Algorithms for random fractals," in The Science of Fractal Images, H. O. Peitgen and D. Saupe, Eds. New York: Springer-Verlag, 1988, pp. 71-136.

[30] J. S. Bendat and A. G. Piersol, Random Data Analysis and Measurement Procedures. New York: Wiley, 1986.

[31] A. K. Fung and M. F. Chen, "Numerical simulation of scattering from simple and composite random surfaces," J. Opt. Soc. Amer. A, vol. 2. no. 12 , pp. 2274-2284, 1985.

[32] E. L. Church, "Comments on the correlation length," in Proc. Soc. Photo-Opt. Instrum. Eng., vol. 680, pp. 102-111, 1986.

[33] E. L. O'Neill and A. Walther, "A problem in the determination of correlation functions," J. Opt. Soc. Amer., vol. 67, no. 8, pp. 1125-1126, 1977.

[34] E. R. Freniére, E. L. O'Neill, and A. Walther, "Problem in the determination of correlation functions II," J. Opt. Soc. Amer., vol. 69, no. 4, pp. 634-635, 1979.

[35] R. T. Austin, A. W. England, and G. H. Wakefield, "Special problems in the estimation of power-law spectra as applied to topographical modeling," IEEE Trans. Geosci. Remote Sensing, vol. 32, pp. 928-939, July 1994.

[36] O. I. Yordanov and K. Ivanova, "Description of surface roughness as an approximate self-affine random structure," Surface Sci., nos. 331-333, pp. 1043-1049, 1995.

[37] F. Mattia, J. C. Souyris, T. Le Toan, D. Casarano, F. Posa, and M. Borgeaud, "On the surface roughness characterization for SAR data analysis," in Proc. Int. Geoscience and Remote Sensing Symp. (IGARSS), Singapore, 1997, pp. 898-900.

[38] S. R. Brown and C. H. Scholz, "Broad bandwidth study of the topography of natural rock surfaces," J. Geophys. Res., vol. 90, no. B14, pp. $12575-12582,1985$.
[39] B. A. Campbell and J. B. Garwin, "Lava flow topographic measurements for radar data interpretation," Geophys. Res. Lett., vol. 20, no. 9, pp. 831-834, 1993

[40] E. I. Thorsos, "The validity of the Kirchhoff approximation for rough surface scattering using a Gaussian roughness spectrum," J. Acoust. Soc. Amer., vol. 83, no. 1, pp. 78-92, 1988.

[41] H. J. Eom and A. K. Fung, "A comparison between backscattering coefficients using Gaussian and non-Gaussian surface statistics," IEEE Trans. Antennas Propagat., vol. AP-31, pp. 635-638, July 1983.

[42] S. C. Wu, M. F. Chen, and A. K. Fung, "Scattering from nonGaussian randomly rough surfaces-Cylindrical case," IEEE Trans. Geosci. Remote Sensing, vol. 26, pp. 790-798, Nov. 1988.

[43] K. Sarabandi and Y. Oh, "Effect of antenna footprint on the statistics of radar backscattering from random surfaces," in Proc. Int. Geoscience and Remote Sensing Symp. (IGARSS), Firenze, Italy, 1995, pp. 927-929.

[44] C. Y. Hsieh, A. K. Fung, G. Nesti, A. J. Sieber, and P. Coppo, "A further study of the IEM surface scattering model," IEEE Trans. Geosci. Remote Sensing, vol. 35, pp. 901-909, July 1997.

[45] A. Ishimaru, C. Le, Y. Kuga, L. A. Sengers, and T. K. Chan, "Polarimetric scattering theory for high slope rough surfaces-Summary," $J$. Electromagn. Waves Applicat., vol. 10, no. 4, pp. 489-491, 1996.

[46] A. Ishimaru, J. S. Chen, P. Phu, and K. Yoshitomi, "Numerical, analytical, and experimental studies of scattering from very rough surfaces and backscatter enhancement," Waves Random Media, vol. 1, no. 3, pp. 91-107, 1991

[47] C. Y. Hsieh and A. K. Fung, "Application of an extended IEM to multiple scattering and backscatter enhancement," in Proc. Int. Geoscience and Remote Sensing Symp. (IGARSS), Singapore, 1997, pp. 702-704.

[48] D. L. Jaggard and X. Sun, "Scattering from fractally corrugated surfaces," J. Opt. Soc. Amer. A, vol. 7, pp. 1131-1139, June 1990.

[49] H. Johnsen, L. Lauknes, and T. Guneriussen, "Geocoding of fastdelivery ERS-1 SAR image mode product using DEM data," Int. J. Remote Sensing, vol. 16, no. 11, pp. 1957-1968, 1995.

[50] L. M. H. Ulander, "Radiometric slope correction of synthetic-aperture radar images," IEEE Trans. Geosci. Remote Sensing, vol. 34, pp. 1115-1122, Sept. 1996.

[51] G. Franceschetti, M. Migliaccio, D. Riccio, and G. Schirinzi, "SARAS: A synthetic aperture radar (SAR) raw signal simulator," IEEE Trans. Geosci. Remote Sensing, vol. 30, pp. 110-123, Jan. 1992.

[52] F. T. Ulaby, R. K. Moore, and A. K. Fung, Microwave Remote Sensing Dedham, MA: Artech House, 1986, vol. III.

[53] G. G. Schaber, J. F. McCauley, C. S. Breed, and G. R. Olhoeft, "Shuttle imaging radar: Physical controls on signal penetration and subsurface scattering in the Eastern Sahara," IEEE Trans. Geosci. Remote Sensing, vol. GE-24, pp. 603-623, July 1986.

[54] A. Remond and J. P. Deroin, "Empirical and theoretical backscattering behavior as a function of roughness for arid land surfaces," in Proc. Int. Geoscience and Remote Sensing Symp. (IGARSS), Singapore, 1997, pp. $1612-1614$.

[55] R. E. Glazman and P. W. Weichman, "Statistical geometry of a smal surface patch in a developed sea," J. Geophys. Res., vol. 94, no. C4, pp. 4998-5010, 1989.

Wolfgang Dierking received the diploma degree in geophysics from the University of Hamburg, Germany, in 1985, and the Ph.D. degree in physics from the University of Bremen, Germany, in 1989.

From 1990 to 1993, he was with the Alfred-Wegener Institute for Polar and Marine Research, Bremerhaven, Germany, where he worked on microwave remote sensing of snow and ice and on measurements of the sea ice surface topography by means of laser altimetry. From 1993 to 1995, he was with the Remote Sensing Group at Chalmers University of Technology, Goteborg, Sweden, where he was involved in the experimental and theoretical research of sea ice radar signatures. Since 1996, he has been an Associate Research Professor at the Danish Center for Remote Sensing, Technical University of Denmark, Lyngby. His current research deals with applications of SAR polarimetry and interferometry in geoscience. 